Hydrol. Earth Syst. Sci. Discuss., 8, 5917-5967, 2011 www.hydrol-earth-syst-sci-discuss.net/8/5917/2011/ doi:10.5194/hessd-8-5917-2011

(c) Author(s) 2011. CC Attribution 3.0 License.
Hydrology and Earth System Sciences Discussions

This discussion paper is/has been under review for the journal Hydrology and Earth System Sciences (HESS). Please refer to the corresponding final paper in HESS if available.

\title{
Mass transfer effects in 2-D dual-permeability modeling of field preferential bromide leaching with drain effluent
}

H. H. Gerke ${ }^{1}$, J. Dusek ${ }^{2}$, and T. Vogel $^{2}$

${ }^{1}$ Institute of Soil Landscape Research, Leibniz-Centre for Agricultural Landscape Research (ZALF), Eberswalder Strasse 84, 15374 Müncheberg, Germany

${ }^{2}$ Department of Hydraulics and Hydrology, Faculty of Civil Engineering, Czech Technical University in Prague, Czech Republic

Received: 24 May 2011 - Accepted: 6 June 2011 - Published: 22 June 2011

Correspondence to: H. H. Gerke (hgerke@zalf.de)

Published by Copernicus Publications on behalf of the European Geosciences Union.

\section{HESSD}

$8,5917-5967,2011$

Mass transfer effects in 2-D-DPERM modeling

H. H. Gerke et al.

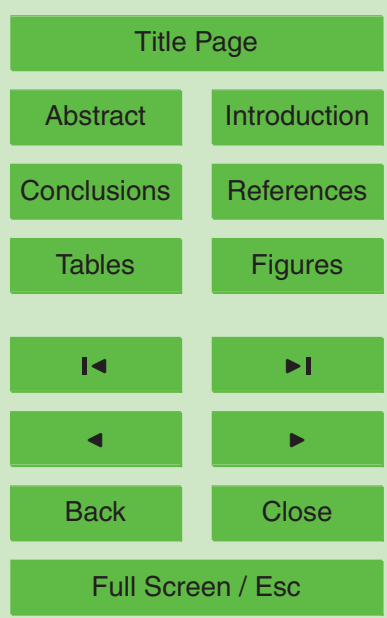

Printer-friendly Version

Interactive Discussion 


\section{Abstract}

Subsurface drained experimental fields are frequently used for studying preferential flow (PF) in structured soils. Considering two-dimensional (2-D) transport towards the drain, however, the relevance of mass transfer coefficients, apparently reflecting small5 scale soil structural properties, for the water and solute balances of the entire drained field is largely unknown. This paper reviews and analyzes effects of mass transfer reductions on $\mathrm{Br}^{-}$leaching for a subsurface drained experimental field using a numerical 2-D dual-permeability model (2D-DPERM). The sensitivity of the "diffusive" mass transfer component on bromide $\left(\mathrm{Br}^{-}\right)$leaching patterns is discussed. Flow and transport is simulated in a 2-D vertical cross-section using parameters, boundary conditions (BC), and data of a $\mathrm{Br}^{-}$tracer irrigation experiment on a subsurface drained field $\left(5000 \mathrm{~m}^{2}\right.$ area) at Bokhorst (Germany), where soils have developed from glacial till sediments. The 2D-DPERM simulation scenarios assume realistic irrigation and rainfall rates, and Br-application in the soil matrix (SM) domain. The mass transfer reduction controls 5 preferential tracer movement and can be related to physical and chemical properties at the interface between flow path and soil matrix in structured soil. A reduced solute mass transfer rate coefficient allows a better match of the $\mathrm{Br}^{-}$mass flow observed in the tile drain discharge. The results suggest that coefficients of water and solute transfer between PF and SM domains have a clear impact on $\mathrm{Br}^{-}$effluent from the drain. Amount and composition of the drain effluent is analyzed as a highly complex interrelation between temporally and spatially variable mass transfer in the 2-D vertical flow domain that depends on varying "advective" and "diffusive" transfer components, the spatial distribution of residual tracer concentrations, and the lateral flow fields in both domains from plots of the whole subsurface drained field. The local-scale soil structural effects (e.g., such as macropore wall coatings), here conceptualized as changes in mass transfer coefficients, can have a clear effect on leaching at the plot and fieldscales.

\section{HESSD}

8, 5917-5967, 2011

\section{Mass transfer effects in 2-D-DPERM modeling}

H. H. Gerke et al.

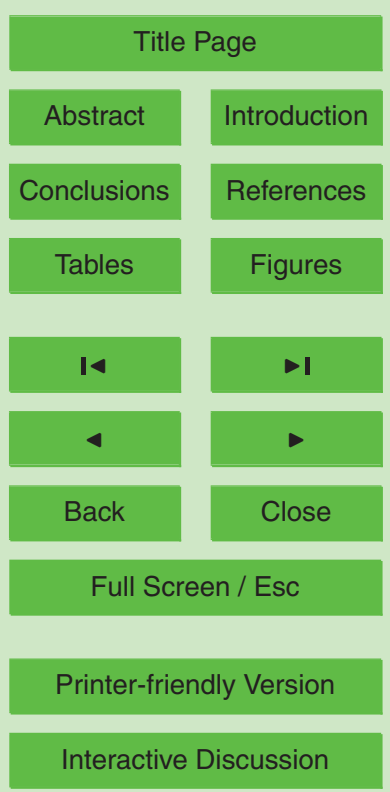




\section{Introduction}

Preferential flow (PF) has frequently been described in soil hydrology and fractured rock hydrology as non-uniform percolation of water, which is bypassing relevant volume fractions of a porous medium along preferred flow paths (e.g., Flury et al., 1994; 5 Berkowitz, 2002; Jarvis, 2007). One major problem associated with the occurrence of PF is that it limits the filter function of the rock matrix or the soil matrix (SM) for solutes, colloids, particles or other components that are transported along with water in flow paths. Among the various porous systems (i.e., soils, fractured rocks, sediments), structured soils of intensively cropped arable land with subsurface drains are of particular environmental concern with respect to unintended water pollution by agricultural chemicals (e.g., Stamm, 1998; Kohler et al., 2001; Stone and Wilson, 2006). Preferential flow has been identified as a major process responsible for the transport of surface-applied pesticides to subsurface drains, in particular, in the medium- and fine-textured soils across the US (e.g., Kladivko et al., 2001) and Europe (e.g., Brown 15 and van Beinum, 2009). Furthermore, macropore flow towards agricultural subsurface drains contributes to nitrogen losses to streams (e.g., Vidon and Cuadra, 2010), and phosphorous leaching (e.g., Gentry et al., 2007; Tiemeyer et al., 2009), which significantly affect both, the quality of groundwater and the eutrophication of surface waters (de Jonge et al., 2002). Soil structure-induced hydraulic connectivity between the soil surface and the drain increases the potential for initiation of "short-circuiting" flux of water (Shipitalo et al., 2004; Kohler et al., 2005; Nielsen et al., 2010), which pushes tracer and even colloids towards subsurface drains (e.g., Akay and Fox, 2007; Akay et al., 2008; Nielsen et al., 2011) in a yet largely unpredictable way.

Subsurface drained plots and fields have been utilized for experimental studies to 25 improve understanding of larger-scale PF and associated transport processes, (e.g., Zehe and Flühler, 2001; Fortin et al., 2002; Kohler et al., 2003). These studies assume that the subsurface drained area can be viewed as a field-scale lysimeter (Richard and Steenhuis, 1988) that integrates all effects of soil and subsurface spatial heterogeneity and structures occurring at the field site. Although limitations have been identified for
HESSD

$8,5917-5967,2011$

\section{Mass transfer effects in 2-D-DPERM modeling}

H. H. Gerke et al.

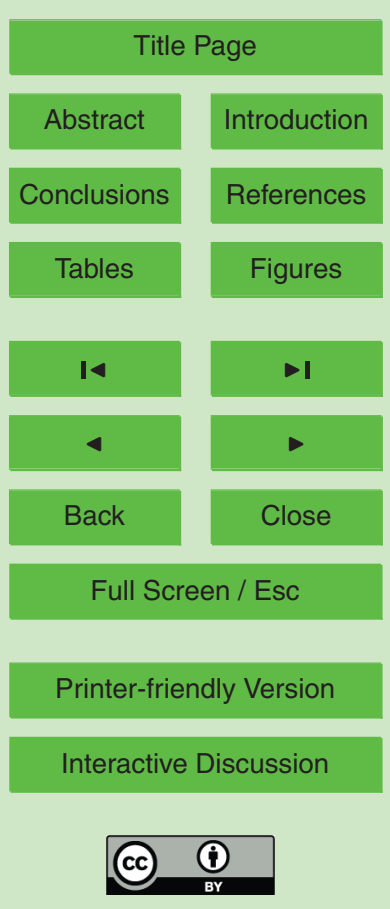


studying pesticide transport (e.g., Jacobsen and Kjaer, 2007), the concept is useful where tile drainage accounts for most of the drainage from the hydrological catchment ( $\mathrm{Li}$ et al., 2010); conditions that are frequently assumed for agricultural post-glacial soil landscapes where relatively low permeable till sediments are forming the bottom 5 boundary (e.g., Villholth et al., 1998; Wichtmann et al., 1998; Jaynes et al., 2001). Here, the drain effluent triggered by preferential flow is typically characterized by relatively large but short-lived solute concentration peaks and a reversed peak dynamic with largest concentrations during first drainage event after application (Kladivko et al., 2001; Gärdenäs et al., 2006).

10 Attempts to describe observed tile effluent patterns by accounting for soil structure effects included one-dimensional (1-D) and two-dimensional (2-D) numerical singleand dual-domain models (e.g., Haws et al., 2005; mobile-immobile: Boivin et al., 2006; Köhne et al., 2006) and transfer functions (e.g., Gaur et al., 2006) among other approaches (e.g., Kohler et al., 2003). The dual-permeability model (DPERM) de15 scribes transient flow of water and transport of solutes in structured soil under variablysaturated conditions within two interacting pore domains (Gerke, 2006). The various DPERM approaches assume either gravity-driven flow in macropores (e.g., Larsson and Jarvis, 1999; Larsbo et al., 2005) or Darcian flow in a more permeable domain (e.g., Gerke and van Genuchten, 1993a). While conceptually equivalent, flow in the

ity in the other (ç Šminek currently evolving that include film flow (Nimmo, 2010), travelling dispersive waves (Di Pietro et al., 2003), and gravity-driven viscous flow (Hincapie and Germann, 2009) among others (see Gerke et al., 2010).

While the two-domain approach introduces effective macroscopic parameters that are difficult to observe (e.g., kinetic mass transfer terms), more explicit single domain formulations require geometric information that are also not easily available (e.g., Klaus and Zehe, 2011), such as the spatially explicit representation of macropore structures as connected pathways (Klaus and Zehe, 2010). Furthermore, local nonequilibrium
HESSD

8, 5917-5967, 2011

\section{Mass transfer effects in 2-D-DPERM modeling}

H. H. Gerke et al.

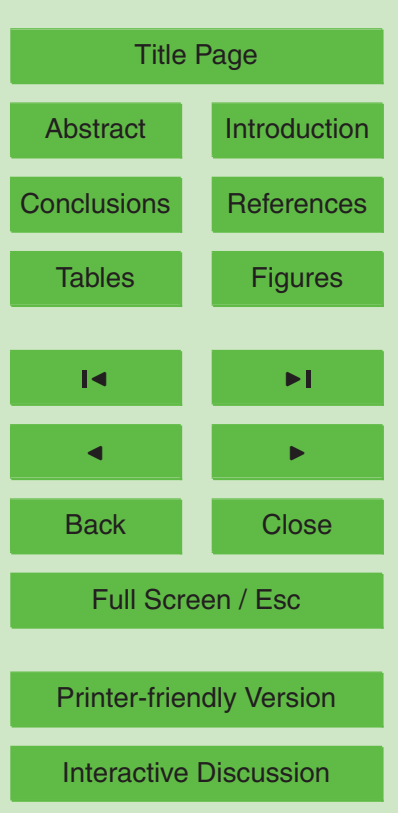


can occur that has been described as a major aspect of preferential flow (Jarvis, 2007) in addition to effects of soil spatial heterogeneity. Local differences in pressure head or solute concentrations are often related to small-scale soil structural features (e.g., Vervoort et al., 1999; Ersahin et al., 2002), and differences in preferential flow were 5 found to be related with soil structural development (Shaw et al., 2000) or resulting from compaction (Coquet et al., 2005). Nonequilibrium conditions induce local mass transfers that are depending on structural geometries and hydraulic and transport properties of aggregates and biopores, or sorption and diffusion properties of burrow walls or clay-organic coatings (e.g., Jarvis et al., 2009). Macropore wall coatings have also 10 been reported to significantly affect transport of reactive solutes in structured soil (e.g., Mallawatantri et al., 1996; Bundt et al., 2001). This is because not only hydraulic (Gerke and Köhne, 2002) and diffusion properties (Köhne et al., 2002a) but also sorption properties of macropore walls (Hansen et al., 1999) and the organic matter (OM) composition of coatings can be different from the bulk soil (Ellerbrock and Gerke, 2004). It is 15 likely to assume that during non-equilibrium type of PF flow, the reactive solutes in the rapidly percolating solution interact preferably with the solids at and near the flow path surfaces (e.g., Youngs and Leeds-Harrison, 1990). Assuming that mineral particles are mostly encased by $\mathrm{OM}$, sorption properties of a structured soil are largely controlled by the OM composition of linings along worm burrows (e.g., Turner and Steele, 1988;

Stehouwer et al., 1993); the OM composition can even be spatially distributed at the mm-scale (Ellerbrock et al., 2009; Leue et al., 2010). Further discussions about the relevance of locally-different properties of PF paths on the prediction of reactive transport (i.e., of cadmium ( $\mathrm{Cd}$ ) during nonequilibrium conditions) can be found elsewhere (Dusek et al., 2010).

25 Because of the complexity of local properties in structured soil, effects of mass exchange on solute leaching are still poorly understood. The solute mass transfer coefficient based on first-order kinetic (cf., Ebel et al., 2009) was found highly sensitive in a 1-D vertical study (Gerke and Köhne, 2004). For the 2D-DPERM simulation of flow and transport in a vertical cross section, the mass transfer processes are additionally
HESSD

8, 5917-5967, 2011

\section{Mass transfer effects in 2-D-DPERM modeling}

H. H. Gerke et al.

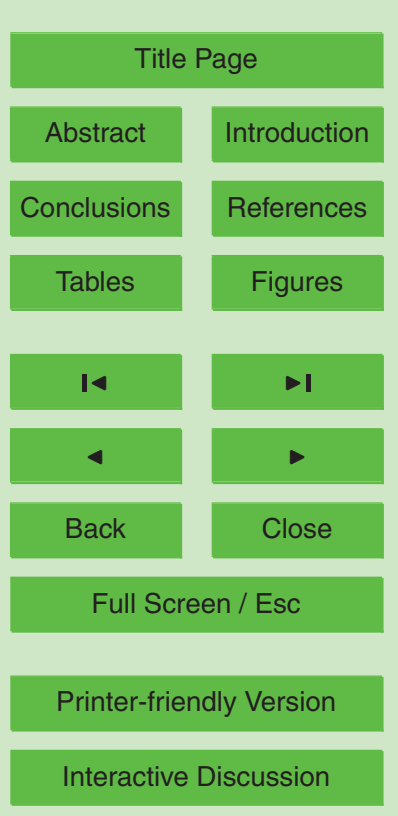


affected by lateral processes and more complex boundary conditions (e.g., Dusek et al., 2008). For 1-D vertical cadmium (Cd) leaching in heavy clay soil (Dusek et al., 2010), the Cd distribution between domains assuming preferential particle-facilitated transport, only slight effects of a reduction of the solute exchange coefficients were re5 ported probably because of the already low permeable SM domain; here, for reactive solutes the sensitivity of exchange coefficients was low compared to sorption effects.

For conservative tracer experiment at Bokhorst field site (e.g., Köhne and Gerke, 2005), the 2D-DPERM was able to capture the basic effects of PF considering three scales (i.e., structure, pedon, and plot). In addition to local nonequilibrium effects that 10 dominated in 1-D, the 2D-DPERM analyses revealed that the conditions at the soil surface, near the water table, and of the field-scale mixing were significantly influencing the effluent concentrations (Gerke et al., 2007). The analysis of effects of the boundary conditions (BC) at the soil surface on $\mathrm{Br}^{-}$leaching (Dusek et al., 2008) suggested that the applied $\mathrm{Br}^{-}$mainly entered the SM domain before being transferred to the $\mathrm{PF}$ domain for rapid downward leaching at the Bokhorst site. However, it remained unclear how mass transfer reductions contributed to the resulting approximation of effluent concentrations. While in a 1D-DPERM analysis (Gerke and Köhne, 2004), mass transfer varies only vertically, mass transfer reductions in the 2D-DPERM model interact with the lateral flow fields of both domains in more complex ways.

The objective of this paper is to review and analyze effects of soil structure-related mass transfer reductions on $\mathrm{Br}^{-}$leaching with drain effluent under 2-D flow conditions. We want to improve understanding of between-domain mass transfer in a vertical cross-section and how these mass transfer effects propagate to describe field-scale drain effluent signals. This study focuses on a previously selected simulation scenario that assumes realistic irrigation and rain intensities, $\mathrm{Br}^{-}$application in the SM domain and flux-type solute BC. The scenario is based on a stepwise model calibration of (a) the hydraulic part of the model by using tile drain discharge, soil moisture, and matric potential data and (b) the mass transfer coefficients from comparisons with $\mathrm{Br}$ effluent data.

\section{HESSD}

$8,5917-5967,2011$

\section{Mass transfer effects in 2-D-DPERM modeling}

H. H. Gerke et al.

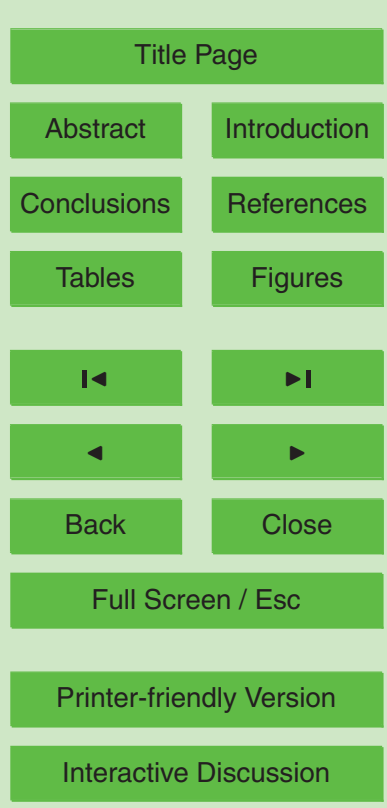




\section{Material and methods}

\subsection{Experimental}

The data are from the experimental site "Bokhorst" located about $25 \mathrm{~km}$ south of the city of Kiel in Northern Germany (Fig. 1a). At this tile-drained arable field, an area 5 of about $5000 \mathrm{~m}^{2}$ is drained by a system of PVC drain pipes installed at about $0.8-$ $1 \mathrm{~m}$ below the soil surface. The drain pipes are connected to a monitoring station equipped with a Venturi flume for the measurement of drain discharge rates and with an automated water sampler for determining effluent concentrations. At this gently sloped field, a spatially heterogeneous distribution of mostly finer-textured soils can be found that developed from glacial till sediments; soil types are ranging from Stagnic Calcaric Regosol (Fig. 1b) to poorly drained Dystric Gleysol (FAO, 1998). The cultivated Ap horizon (0-0.3 m soil depth) had about $20 \%$ clay and $30 \%$ silt. Clay contents generally decreased with soil depth to about $10 \%$ at the $0.7-$ to $1.1-\mathrm{m}$ depth. Soil structures are subangular (0-0.3 $\mathrm{m}$ soil depth), angular blocky $(0.3-0.95 \mathrm{~m})$, and coherent (below 0.95-m depth). More details can be found elsewhere (e.g., Lennartz et al., 1999; Gerke and Köhne, 2004). The site has been used for tracer experiments before; at that time (Wichtmann et al., 1998), tracer application was carried out along a wide strip all across the drained catchment perpendicular to the tile lines (Fig. 1a). This previous experiment has led to a simplified representation of the whole drain catchment as 1-D vertical soil column (Fig. 1c) with "effective" properties in which discharge was regarded as seepage at the bottom of the column where a constant water table was assumed (Gerke and Köhne, 2004).

For the 2-D analysis here, the 1996/97 tracer experiment was selected (Köhne and Gerke, 2005) that was carried out on a $10 \mathrm{~m}$ long plot between two parallel drains of $2511.8 \mathrm{~m}$ drain spacing of the same field (Fig. 2a). The bromide (KBr) tracer was applied on one side of the plot area along a $10 \mathrm{~m}$ long and $0.3 \mathrm{~m}$ wide strip at $0.85-1.15 \mathrm{~m}$ distance parallel to a tile line (cf., Fig. 1 in Dusek et al., 2008). Instrumentation included a weather station (i.e., precipitation, air temperature and humidity recorded in 10-min

HESSD

8, 5917-5967, 2011

\section{Mass transfer effects in 2-D-DPERM modeling}

H. H. Gerke et al.

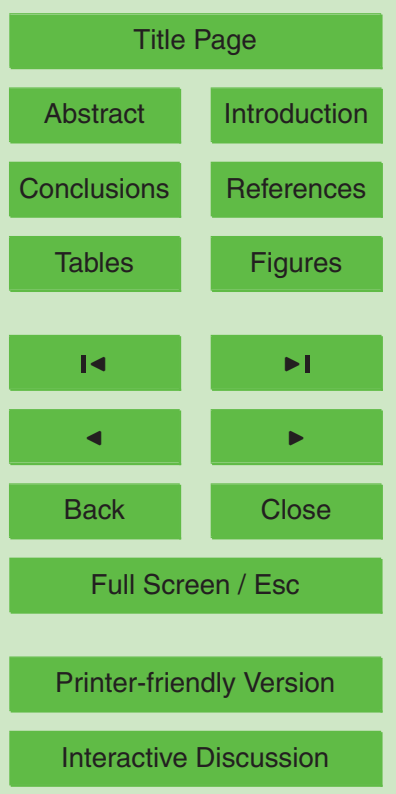


intervals), piezometers, and tensiometers installed at 1,3 , and $5 \mathrm{~m}$ distance from the tile line in $0.15,0.35,0.5,0.6$, and $0.8 \mathrm{~m}$ depths. Winter wheat (Triticum aestivum L.) was growing on the field during the experiment. More details on the 1996/97 tracer experiment can be found in Köhne and Gerke (2005) and Gerke et al. (2007).

The present analysis is focusing on data following the tracer application on 25 March 1997 (Day 97; counted from a first bromide application on 18 December 1996), when $6.4 \mathrm{~kg}$ of $\mathrm{KBr}$ salt $\left(4.3 \mathrm{~kg} \mathrm{Br}^{-}\right)$was applied in solid form to the soil surface. The plot area between two tile lines of about $120 \mathrm{~m}^{2}$ was then irrigated in 30 min irrigation intervals alternating for the 2 half plot areas of $60 \mathrm{~m}^{2}$ assuming symmetry 10 in drainage towards either side as follows (Fig. 2b): Irrigation started at the plot-side with the $\mathrm{Br}$ application strip; then the opposite side was irrigated for the next $30 \mathrm{~min}$, such that the bromide-strip side was irrigated 5-times at a rate of $13.4 \mathrm{~mm} \mathrm{~h}^{-1}$ on Day $97\left(33.5 \mathrm{~mm}\right.$ total) and 4-times with an intensity of $12.6 \mathrm{~mm} \mathrm{~h}^{-1}$ on Day $98(25.2 \mathrm{~mm}$ total). The $\mathrm{KBr}$ salt had completely dissolved by the end of the first $4.5-\mathrm{h}$ irrigation

period on Day 97 . The time resolution of the tile outflow measurements and the water sampling for the period of interest (Day 97-Day 103) ranged from 2 to $6 \mathrm{~h}$. $\mathrm{Br}^{-}$mass

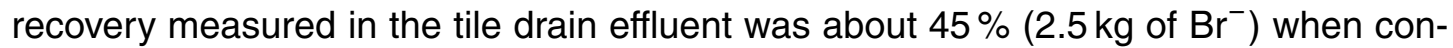
sidering the total period of 120 days, and $6 \%\left(0.3 \mathrm{~kg} \mathrm{Br}^{-}\right)$during the 2-days irrigation period (Köhne and Gerke, 2005).

\subsection{Modeling}

For the analysis, the soil is considered as a double continuum system because an explicit treatment of larger and more continuous pores appeared unfeasible for this structured soil that is characterized by differently-sized fissures and biopores forming a relatively dense and seemingly inter-connected network (e.g., Fig. 1b). Here, the 25 numerical 2D-DPERM water flow and solute transport model S2D is used (Vogel et al., 2000a). The dual-permeability approach (Gerke and van Genuchten, 1993a) assumes that a structured soil can conceptually be separated into two mobile interacting pore domains. The 2-D flow of water in the SM domain (subscript $\mathrm{m}$ ) and the PF domain 5924
HESSD

8, 5917-5967, 2011

\section{Mass transfer effects in 2-D-DPERM modeling}

H. H. Gerke et al.

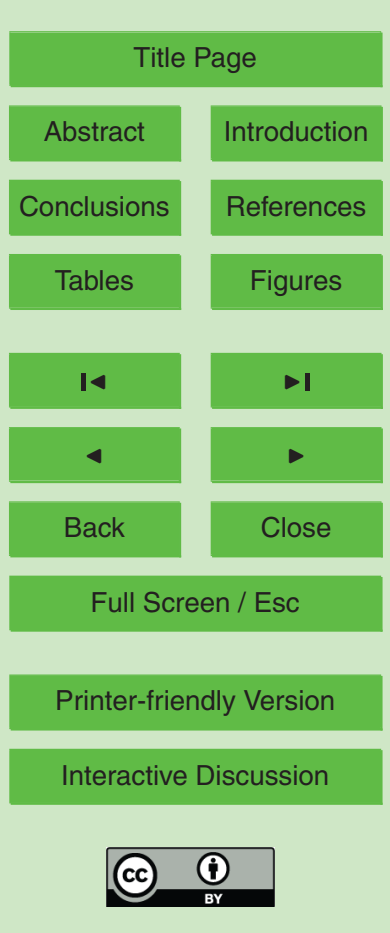


(subscript f) is described with two coupled Richards' equations:

$C_{\mathrm{f}} \frac{\partial h_{\mathrm{f}}}{\partial t}=\nabla \cdot\left(\mathbf{K}_{\mathrm{f}} \nabla h_{\mathrm{f}}\right)+\nabla \cdot\left(\mathbf{K}_{\mathrm{f}} \nabla z\right)-\frac{\Gamma_{\mathrm{w}}}{w_{\mathrm{f}}}$

$C_{\mathrm{m}} \frac{\partial h_{\mathrm{m}}}{\partial t}=\nabla \cdot\left(\mathbf{K}_{\mathrm{m}} \nabla h_{\mathrm{m}}\right)+\nabla \cdot\left(\mathbf{K}_{\mathrm{m}} \nabla z\right)+\frac{\Gamma_{\mathrm{w}}}{w_{\mathrm{m}}}+S_{\mathrm{m}}$

HESSD

8, 5917-5967, 2011

where for each pore domain, $h$ denotes the pressure head (L), $\mathbf{K}$ the hydraulic conductivity tensor $\left(\mathrm{LT}^{-1}\right)$, and $C=d \theta / d h$ the specific soil water capacity $\left(\mathrm{L}^{-1}\right)$ with $\theta$, 5 the volumetric water content $\left(\mathrm{L}^{3} \mathrm{~L}^{-3}\right) ; w_{\mathrm{f}}$ is the relative volumetric fraction of the $\mathrm{PF}$ domain, $w_{m}=1-w_{f}, S_{m}$ is a sink term for root water uptake $\left(\mathrm{T}^{-1}\right)$ from the SM domain, $z$ is the vertical coordinate, taken to be positive upward $(L), t$ is time $(T)$, and $\Gamma_{w}$ is the water transfer term describing the inter-domain water exchange $\left(\mathrm{T}^{-1}\right)$. Root water uptake from the PF domain is neglected because of its relatively small water retention. 10 Subscripts $f$ and $m$ in Eq. (1) indicate the domain-specific (local) variables and parameters. The bulk soil volume-related (i.e., composite) transfer term, $\Gamma_{w}$, is assumed to be proportional to the local pressure head difference between the PF- and the SM-pore system (Gerke and van Genuchten, 1993b) as:

$\Gamma_{\mathrm{w}}=\alpha_{\mathrm{w}}\left(h_{\mathrm{f}}-h_{\mathrm{m}}\right)=\alpha_{\mathrm{ws}} K_{\mathrm{a}}^{\mathrm{r}}\left(h_{\mathrm{f}}-h_{\mathrm{m}}\right)$

15 where $\alpha_{\mathrm{w}}$ is the first-order water transfer rate coefficient $\left(\mathrm{L}^{-1} \mathrm{~T}^{-1}\right)$ evaluated (Ray et al., 2004) as $\alpha_{\mathrm{w}}=\alpha_{\mathrm{ws}} K_{\mathrm{a}}^{\mathrm{r}}$ with $\alpha_{\mathrm{ws}}$, the water transfer rate coefficient at saturation $\left(\mathrm{L}^{-1} \mathrm{~T}^{-1}\right)$ and with $K_{\mathrm{a}}^{\mathrm{r}}$, the relative hydraulic conductivity function $(-)$ of the interface (e.g., the aggregate surface; subscript a) between the domains; the value of $K_{a}^{r}$ is taken as the minimum of PF domain and SM domain conductivities evaluated for upstream pres20 sure (i.e., $K_{\mathrm{a}}^{\mathrm{r}}=\min \left(K_{\mathrm{f}}^{\mathrm{r}}\left(h_{\mathrm{f}}\right)\right),\left(K_{\mathrm{m}}^{\mathrm{r}}\left(h_{\mathrm{f}}\right)\right)$ for $h_{\mathrm{f}} \geq h_{\mathrm{m}}$ and $K_{\mathrm{a}}^{\mathrm{r}}=\min \left(K_{\mathrm{f}}^{\mathrm{r}}\left(h_{\mathrm{m}}\right)\right),\left(K_{\mathrm{m}}^{\mathrm{r}}\left(h_{\mathrm{m}}\right)\right)$ for $\left.h_{\mathrm{f}}<h_{\mathrm{m}}\right)$. The coefficient $\alpha_{\mathrm{ws}}$ lumps the exchange coefficients of previous formulations (e.g., Gerke and van Genuchten, 1993b) and can account for mass transfer reductions due to, for instance, aggregate coating effects (e.g., Gerke and Köhne, 2002). The composite boundary flux of soil water $q\left(\mathrm{LT}^{-1}\right)$ is defined as

${ }_{25} \quad q=\mathbf{n q}_{\mathrm{f}} w_{\mathrm{f}}+\mathbf{n q}_{\mathrm{m}} w_{\mathrm{m}}$

\section{Mass transfer effects in 2-D-DPERM modeling}

H. H. Gerke et al.

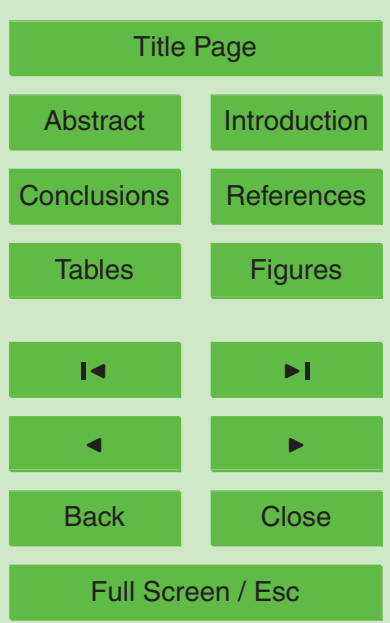

Printer-friendly Version

Interactive Discussion 
where $\mathbf{n}$ is the unit normal to the boundary $(-)$ and $\mathbf{q}$ the vector of soil water flux $\left(\mathrm{LT}^{-1}\right)$. This flux, $q$, is used to calculate the drainage intensity from the simulated 2-D domain.

The 2-D transport of solutes in a dual-permeability soil involves two coupled advection-dispersion equations (e.g., Vogel et al., 2000) as:

$$
\begin{aligned}
& \frac{\partial\left(\theta_{\mathrm{f}} c_{\mathrm{f}}\right)}{\partial t}=\nabla \cdot\left(\theta_{\mathrm{f}} \mathbf{D}_{\mathrm{f}} \nabla c_{\mathrm{f}}\right)-\nabla \cdot\left(\mathbf{q}_{\mathrm{f}} \mathbf{c}_{\mathrm{f}}\right)+\frac{\boldsymbol{\Gamma}_{\mathrm{s}}}{\mathbf{w}_{\mathrm{f}}} \\
& \frac{\partial\left(\theta_{\mathrm{m}} c_{\mathrm{m}}\right)}{\partial t}=\nabla \cdot\left(\theta_{\mathrm{m}} \mathbf{D}_{\mathrm{m}} \nabla c_{\mathrm{m}}\right)-\nabla \cdot\left(\mathbf{q}_{\mathrm{m}} \mathbf{c}_{\mathrm{m}}\right)+\frac{\boldsymbol{\Gamma}_{\mathrm{s}}}{\mathbf{w}_{\mathrm{m}}}
\end{aligned}
$$

where $c$ is solute concentration $\left(\mathrm{ML}^{-3}\right)$ and $\mathbf{D}$ is the dispersion coefficient tensor $\left(\mathrm{L}^{2} \mathrm{~T}^{-1}\right)$. Equation (4) contains no sink term because root uptake of $\mathrm{Br}^{-}$was negligible in previous analysis (Gerke et al., 2007); the term $\Gamma_{\mathrm{s}}$ is the solute mass transfer term $\left(\mathrm{ML}^{-3} \mathrm{~T}^{-1}\right)$ evaluated as (Gerke and van Genuchten, 1996):

$10 \Gamma_{\mathrm{s}}=\Gamma_{\mathrm{w}} c_{i}+\alpha_{\mathrm{s}}\left(c_{\mathrm{f}}-c_{\mathrm{m}}\right)$

in which $c_{i}=c_{\mathrm{f}}$ if water is transferred from the PF domain into the SM domain (i.e., $\Gamma_{\mathrm{w}}$ positive) and $c_{i}=c_{\mathrm{m}}$ if water transfer is in the opposite direction. This solute mass transfer (Eq. 5) considers an "advective" component controlled by the water transfer and a "diffusive" component controlled by the difference in local solute concentrations.

15 The coefficient $\alpha_{\mathrm{s}}$ represents the first-order solute mass transfer coefficient $\left(\mathrm{T}^{-1}\right)$ evaluated as $\alpha_{\mathrm{s}}=\alpha_{\mathrm{ss}} \theta_{\mathrm{a}}^{\mathrm{r}}$, where $\alpha_{\mathrm{ss}}$ is the lumped solute transfer rate coefficient at saturation $\left(\mathrm{T}^{-1}\right)$, and where $\theta_{\mathrm{a}}^{\mathrm{r}}=\theta_{\mathrm{a}} / \theta_{\mathrm{as}}$ is the relative effective saturation of the PF domain (Ray et al., 2004), which is mostly more dynamic than that of the SM domain. Composite solute concentration in the soil (Eq. 6a) and mass flux of solute in the effluent, $j$ $20 \quad\left(\mathrm{ML}^{-2} \mathrm{~T}^{-1}\right)$, are determined from

$$
\begin{aligned}
\theta c & =w_{\mathrm{f}} \theta_{\mathrm{f}} c_{\mathrm{f}}+w_{\mathrm{m}} \theta_{\mathrm{m}} c_{\mathrm{m}} \\
j & =w_{\mathrm{f}} c_{\mathrm{f}} \mathbf{n} \mathbf{q}_{\mathrm{f}}+w_{\mathrm{m}} c_{\mathrm{m}} \mathbf{n} \mathbf{q}_{\mathrm{m}}
\end{aligned}
$$

The two sets of coupled equations (Eqs. 1 and 4) were solved numerically using fully implicit Galerkin finite elements. The numerical discretization of the $5.9 \mathrm{~m}$ wide (i.e., 5926
HESSD

8, 5917-5967, 2011

\section{Mass transfer effects in 2-D-DPERM modeling}

H. H. Gerke et al.

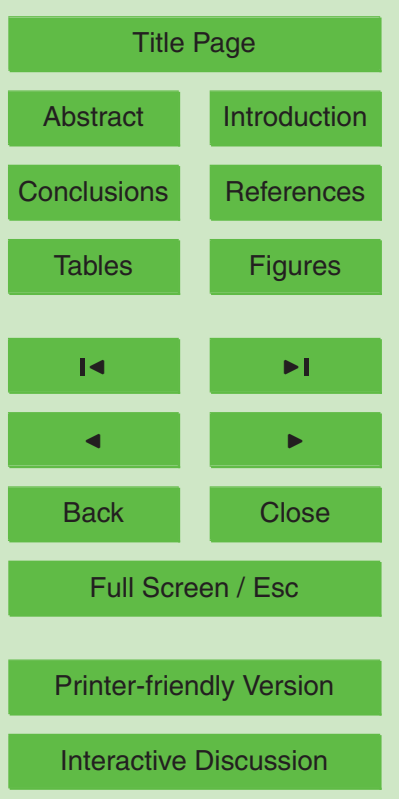


half distance between tiles) and $2 \mathrm{~m}$ deep cross-sectional domain was 4331 rectangular elements; nodal distances $(0.0025-0.02 \mathrm{~m})$ were smaller near the soil surface and around the tile drain (see Gerke et al., 2007 for more details). Flow and transport equations were solved sequentially, beginning with the PF domain and then solving for 5 the SM domain. The transfer terms were evaluated at the previous time level.

The soil hydraulic functions are described using the modified version of the van Genuchten- (VG-) Mualem formulation (van Genuchten, 1980) that introduces a nonzero air-entry pressure head value, $h_{\mathrm{s}}(\mathrm{L})$ (Vogel and Cislerova, 1988; Vogel et al., 2000b):

$$
\begin{aligned}
& \theta(h)=\theta_{\mathrm{r}}+\left(\theta_{\mathrm{m}}-\theta_{\mathrm{r}}\right)\left[1+\left(-\alpha_{\mathrm{VG}} h\right)^{n}\right]^{-m} \\
& K(\theta)=K_{\mathrm{s}}\left(\frac{\theta-\theta_{\mathrm{r}}}{\theta_{\mathrm{s}}-\theta_{\mathrm{r}}}\right)^{1 / 2}\left(\frac{1-F(\theta)}{1-F\left(\theta_{\mathrm{s}}\right)}\right)^{2}
\end{aligned}
$$

where $\theta_{\mathrm{m}}=\theta_{\mathrm{r}}+\left(\theta_{\mathrm{s}}-\theta_{\mathrm{r}}\right)\left[1+\left(-\alpha_{\mathrm{VG}} h_{\mathrm{s}}\right)^{n}\right]^{m}$ and $F(\theta)=\left(1-\left(\frac{\theta-\theta_{\mathrm{r}}}{\theta_{\mathrm{m}}-\theta_{\mathrm{r}}}\right)^{1 / m}\right)^{m} ; \theta_{\mathrm{s}}$ and $\theta_{\mathrm{r}}$ are saturated and residual water contents $\left(\mathrm{L}^{3} \mathrm{~L}^{-3}\right)$, respectively; $n(-)$ and $\alpha_{\mathrm{VG}}\left(\mathrm{L}^{-1}\right)$ are empirical shape parameters with $n>1$ and $m=1-1 / n ; K_{\mathrm{s}}$ is the saturated hydraulic 5 conductivity $\left(\mathrm{LT}^{-1}\right)$.

The soil hydraulic model parameters (Table 1) for $0-30 \mathrm{~cm}$ (Ap horizon) and 30$200 \mathrm{~cm}$ soil depth (C Sd horizon) were the same as used previously (e.g., Gerke and Köhne, 2004). Note that these hydraulic properties were based on laboratory soil core measurements and field infiltration data; while exchange term coefficients (see Sect. 2.3, Table 2) were derived from calibration of an earlier tracer experiment at the same site (Wichtmann et al., 1998). The value of $w_{\mathrm{f}}=0.05$ as volumetric fraction of the PF-domain was based on observations of soil structure including the fraction of dye stained areas. The anisotropy (horizontal $x$ and vertical $y$ directions) of the hydraulic conductivity of $K_{x x} / K_{z z}=3$ for the subsoil below $40 \mathrm{~cm}$ depth was based on

\section{HESSD}

8, 5917-5967, 2011

\section{Mass transfer effects in 2-D-DPERM modeling}

H. H. Gerke et al.

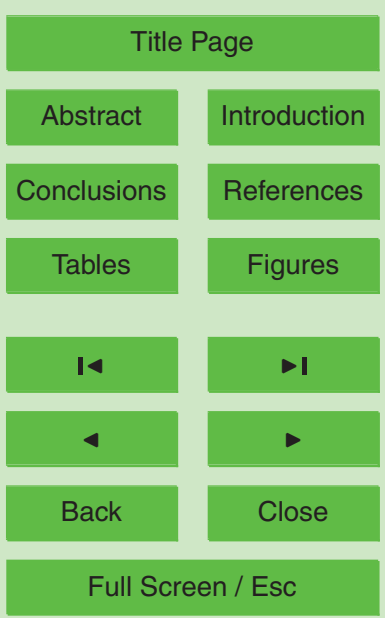

Printer-friendly Version

Interactive Discussion 
The domain-specific parameters were obtained from measured data by a bimodal curve fitting procedure (Durner, 1994) using the SHYPFIT program (Durner, 1993) with a SHYPFIT weighing coefficient of $w_{1}=w_{f}=0.05$, and by subsequently predicting the hydraulic conductivity function (Gerke and Köhne, 2004). For the experimental site, 5 alternative parameterizations have previously been attempted by inverse parameter identification using discharge and effluent as well as piezometer and tensiometer data for 2-D single-domain and 2-D mobile-immobile simulations (Köhne and Gerke, 2005) and by optimization of the domain-specific parameters using bulk soil hydraulic data measured on core samples (Köhne et al., 2002b). Here, we used the parameter val10 ues as before in Gerke et al. (2007) and Dusek et al. (2008) for the 2-D analyses and in Gerke and Köhne (2004) for the 1-D simulation to conserve comparability of results. Soil spatial variability in hydraulic properties and parameter optimization were not considered in this stage of the analysis in order to focus on basic two-domain model descriptions. Although soil spatial heterogeneity can additionally affect inter-domain mass transfer, it was beyond the scope to introduce additional complexity.

For both layers and domains, the dispersion coefficient tensor $\mathbf{D}\left(\mathrm{L}^{2} \mathrm{~T}^{-1}\right)$ was evaluated (Bear, 1972) as:

$D_{i j}=D_{\mathrm{o}} \tau \delta_{i j}+\frac{\lambda_{\mathrm{T}} q}{\theta} \delta_{i j}+\frac{\lambda_{\mathrm{L}}-\lambda_{\mathrm{T}}}{\theta q} q_{i} q_{j}$

where $D_{\mathrm{O}}$ is the molecular diffusion coefficient $\left(\mathrm{L}^{2} \mathrm{~T}^{-1}\right), \lambda_{\mathrm{L}}$ is the longitudinal and $\lambda_{\mathrm{T}}$ 20 the transversal dispersivity $(\mathrm{L}), q$ is the magnitude of the vector of water flux $\left(\mathrm{LT}^{-1}\right)$, $\delta_{i j}$ is the Kronecker delta function $\left(\delta_{i j}=1\right.$ if $i=j$, and $\delta_{i j}=0$ if $\left.i \neq j\right)$. Here, a longitudinal dispersivity of $\lambda_{\mathrm{L}}=20 \mathrm{~cm}$, a transversal dispersivity of $\lambda_{\mathrm{T}}=2 \mathrm{~cm}$, a molecular diffusion coefficient of $D_{0}=1.2 \mathrm{~cm}^{2} \mathrm{~d}^{-1}$, and a dimensionless tortuosity factor evaluated as $\tau=\theta^{7 / 3} / \theta_{\mathrm{S}}^{2}$ (Millington and Quirk, 1961) were again used for both domains and soil horizons.
HESSD

$8,5917-5967,2011$

\section{Mass transfer effects in 2-D-DPERM modeling}

H. H. Gerke et al.

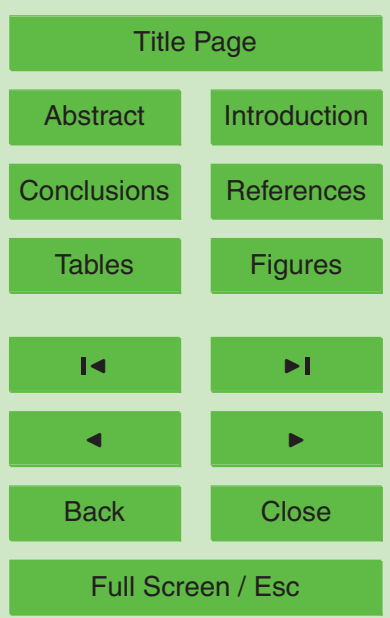

Printer-friendly Version

Interactive Discussion 


\subsection{Mass transfer}

The transfer term parameters (Table 2) were adopted from those of the 1D-DPERM analysis (Gerke and Köhne, 2004) where values of $\alpha_{\mathrm{ws}}=0.006 \mathrm{~cm}^{-1} \mathrm{~d}^{-1}$ and $\alpha_{\mathrm{ss}}=$ $0.006 \mathrm{~d}^{-1}$ for the Ap and of $\alpha_{\text {ws }}=0.004 \mathrm{~cm}^{-1} \mathrm{~d}^{-1}$ and $\alpha_{\mathrm{ss}}=0.004 \mathrm{~d}^{-1}$ for the C Sd hori5 zon were used. These exchange rate coefficients are imitating a reduction of the mass transfer between the domains induced, for instance, by aggregate coatings. Note that mass transfer rates, $\Gamma_{\mathrm{w}}$ and $\Gamma_{\mathrm{s}}$, Eqs. (2) and (5) are not constant; these rates depend on the differences in pressure heads and concentrations between the domains as well as on the pressure-head dependent functions $K_{\mathrm{a}}^{\mathrm{r}}(h)$ and $\theta_{\mathrm{a}}^{\mathrm{r}}(h)$. Values of the exchange 10 rate coefficients have not directly been measured yet. However, for individual soil aggregates from the same site, exchange reductions of similar order of magnitude have been observed from aggregate imbibition and diffusion experiments comparing results for aggregates with intact and removed coatings (Gerke and Köhne, 2002; Köhne et al., 2002a); larger values (i.e., effective transfer coefficients) were obtained by inverse es-

15 timation assuming a 2-D mobile-immobile model (Köhne and Gerke, 2005). Here, only the effects of different $\alpha_{\mathrm{ss}}$-values were tested for conditions of relatively high pore water saturations. Sensitivity studies (not shown here) revealed stronger effects for domainspecific differences in $\mathrm{Br}^{-}$concentrations than for differences in pressure heads. The 4-orders of magnitude differences in $\alpha_{\mathrm{ss}}$-values in the scenarios (Table 2) allow covering nearly the whole range of inter-domain exchange conditions from local equilibrium to non-equilibrium in concentrations. Furthermore, we notice that inter-domain water transfer is already limited by the relatively low value of the saturated hydraulic conductivity, $K_{\mathrm{sm}}$, of the SM-domain for this soil.

\subsection{Initial and boundary conditions}

25 The initial 2-D pressure head distribution on 24 February 1997 (Day 68) was obtained from simulations (Gerke et al., 2007) carried out for the preceding period beginning on 18 December 1996 (Day 0) with a pressure head profile that was obtained from

HESSD

8, 5917-5967, 2011

\section{Mass transfer effects in 2-D-DPERM modeling}

H. H. Gerke et al.

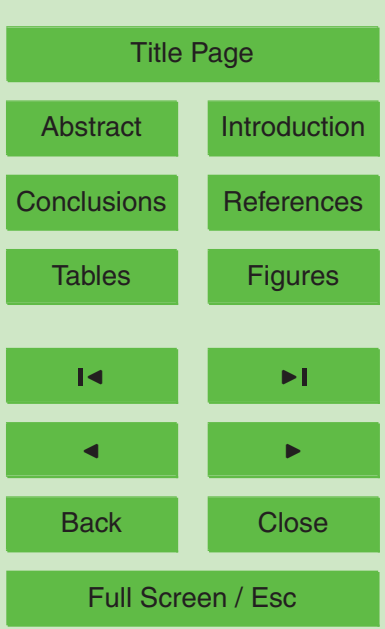

Printer-friendly Version

Interactive Discussion 
tensiometer measurements. As initial condition for solute transport simulations, we used the spatially interpolated residual $\mathrm{Br}^{-}$distribution on Day 68 obtained from soil data from a trench perpendicular to the tile line. Small $\mathrm{Br}^{-}$concentrations were still present in the soil (mainly close to the tile line) resulting from the earlier tracer appli5 cation on Day 0. At that time, 3I (i.e., $1 \mathrm{Im}^{-2}$ ) of a solution containing $333 \mathrm{gl}^{-1} \mathrm{Br}^{-}$ $(1.5 \mathrm{~kg} \mathrm{KBr}$ dissolved in $3 \mathrm{I}$ of water) was sprayed on the $10 \mathrm{~m} \times 0.3 \mathrm{~m}$ strip area. This first tracer application was hampered by extreme weather conditions that led to drain discharge without $\mathrm{Br}^{-}$breakthrough (Köhne and Gerke, 2005).

A flux-type atmospheric BC was imposed at the soil surface to represent rainfall10 and irrigation-induced infiltration and evapotranspiration. The evapotranspiration was estimated as described in Köhne and Gerke (2005). Note that potential evapotranspiration (ETp) was relatively small (i.e., $2.7 \mathrm{~mm}$ ) during the period of interest between Day 97 and 103 (i.e., 25-31 March 1997). A linear root distribution was assumed with the maximum at the soil surface and the minimum at a depth of $1 \mathrm{~m}$. Root water uptake 15 was described using a plant water stress function (Feddes et al., 1978) as in Gerke et al. (2007). Because of the negligibly small ETp, a more realistic root distribution (e.g., adapted to the growth stage of wheat in March) was not considered.

For simulating water infiltration, the applied irrigation rates and measured rain intensities were distributed between domains proportional to volume fractions $w_{m}$ and $w_{f}$. In case the infiltration capacity of the SM-domain was exceeded, any surplus water was redistributed to allow for infiltration into the PF domain (see Dusek et al., 2008). In case irrigation rates exceeded the infiltration capacity of both pore domains at the soil surface, surplus water was balanced and allowed to resume infiltrating into the soil after the end of the daily irrigation periods (e.g., at Days 97.8 and 98.65 in Fig. 3a). In this way, we tried to imitate the infiltration regime and to account for the observation that during irrigation water started ponding in micro-topographic depressions at the surface without creating any significant surface runoff. The simulated infiltration rates (Fig. 3a) reveal the anticipated dynamics of domain-specific distributions of the irrigation as follows: While total infiltration rates remain constant, SM-domain infiltration
HESSD

8, 5917-5967, 2011

\section{Mass transfer effects in 2-D-DPERM modeling}

H. H. Gerke et al.

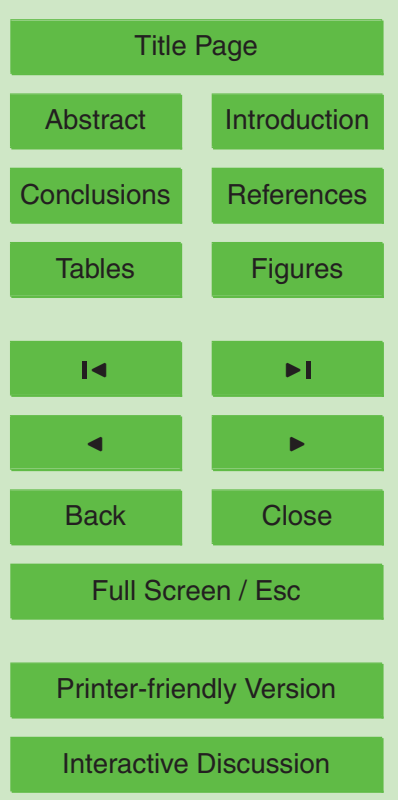


rapidly decreases while infiltration into the PF domain (e.g., through worm burrows and cracks that end at the soil surface) increases due to surface redistribution. For each following 30-min irrigation interval, the SM-domain infiltration rates are starting at a lower level than before because of the increasingly faster saturation of the SM domain at the 5 soil surface. Later, the infiltration into the PF domain starts decreasing indicating that total soil's infiltration capacity is exceeded. After the irrigation, the remaining surplus is allowed infiltrating again proportional to the volume fractions of domains, thereby excluding any further redirection of surplus water from the SM to the PF domain. Thus during the "drainage" of surface storage after the irrigation, less water is directly enter10 ing the PF-domain; most surplus water is entering the SM domain. The alternative of letting ponded surplus water infiltrate directly after each 30-min irrigation interval was not useful because the soil became nearly completely saturated.

For simulating solute transport, a third-type solute BC with prescribed $\mathrm{Br}^{-}$concentrations of the infiltrating water was imposed at the soil surface. The $\mathrm{Br}^{-}$concentration of the application was calculated using the cumulative infiltration flux and the total applied $\mathrm{Br}^{-}$mass (i.e., $4.3 \mathrm{~kg}$ per $10 \mathrm{~m} \times 0.3 \mathrm{~m}$ application strip) only for irrigations during Day 97 according to the observation that no salt was visible on the soil surface afterwards. As a result of previous analysis (Gerke et al., 2007), the total $\mathrm{Br}^{-}$mass was assumed to enter the soil surface only through the SM domain on Day 97 yielding the (30-min intermittent) temporal influx distribution (Fig. 3b) that is largely proportional to simulated SM-domain infiltration rates (Fig. 3a). Imposing these conditions is based on the assumption that $\mathrm{KBr}$ salt, when applied to a relatively moist soil, can rapidly start dissolving and entering the SM-domain's surface layer as $\mathrm{Br}^{-}$solution. Furthermore, the assumption of $\mathrm{Br}^{-}$-free infiltration into the PF-domain implies that direct PF-domain infiltration is not in contact with applied $\mathrm{KBr}$ and that no mixing occurs during redistribution of irrigation water at the soil surface. This somewhat hypothetical split in $\mathrm{Br}^{-}$influx between the domains mainly allows for a more contrasting analysis of the effects of mass transfer reductions on the effluent concentrations. Unfortunately, the information about domain-specific surface BC was not available.
HESSD

8, 5917-5967, 2011

\section{Mass transfer effects in 2-D-DPERM modeling}

H. H. Gerke et al.

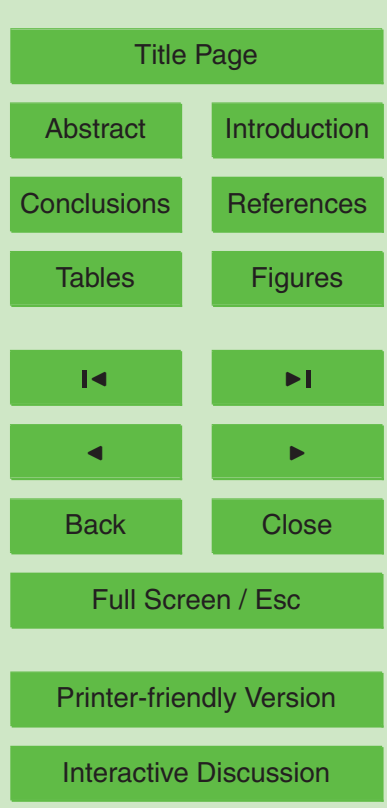


At the bottom, a no-flow BC was imposed in $2 \mathrm{~m}$ depth to account for the negligibly small deep percolation into the underlying relatively dense un-weathered glacial till. At the left and right sides of the 2-D domains (Fig. 2c), a no-flow BC was imposed assuming symmetry perpendicular to drain tiles. For the drain, a seepage face BC was 5 imposed across an "effective" inner tile diameter of $0.04 \mathrm{~m}$; this value was based on number and size of the small openings in the drain tube (Köhne and Gerke, 2005), allowing water effluent under saturated conditions only (i.e., for local pressure head values of $h \geq 0$ ). For simulating $\mathrm{Br}^{-}$leaching out of the drain tile, a zero-gradient solute $\mathrm{BC}$ was ascribed for both the PF and SM domains (i.e., $\mathrm{Br}^{-}$may enter the tile with the 10 effluent water).

\subsection{Plot versus field-scale simulations and pore domains}

The numerical analysis of the experiment involves spatial scales and model domains at four levels (see Fig. 2): (level A) the field-scale (i.e., the drained catchment) with the measurements at the drain outlet, (level B) the plot-scale with the irrigated plot area and the $\mathrm{KBr}$ application strip and with the pits where soil sampling and tensiometer monitoring was carried out, (level C) the macroscopic scale 2-D vertical cross sections for the coupled domains representing lateral flow and transport towards the drain for irrigated plot, and (level D) the local-scale model of the structured soil with the inter-domain redistribution of infiltration at the soil surface and the inter-domain mass transfer processes within the soil. Because of the complexity at the four levels, a stepwise modeling strategy was followed here. The effects of local-scale model parameters (level D) on drain effluent can be physically described in 2-D simulations (level $C$ ) thereby representing various conditions for similar plots (level B) in the field. A comparison of plot simulation results with those of the field-scale effluent data (level A) is, however, only possible after integrating the plot-scale simulations to the field level.

For a simplified integration, one "plot-scale" simulation scenario was carried out for a 2-D cross-section representing the irrigated area between the two drain pipes of about $120 \mathrm{~m}^{2}$ and a second one for the cross-sections representing the half-width area
HESSD

8, 5917-5967, 2011

\section{Mass transfer effects in 2-D-DPERM modeling}

H. H. Gerke et al.

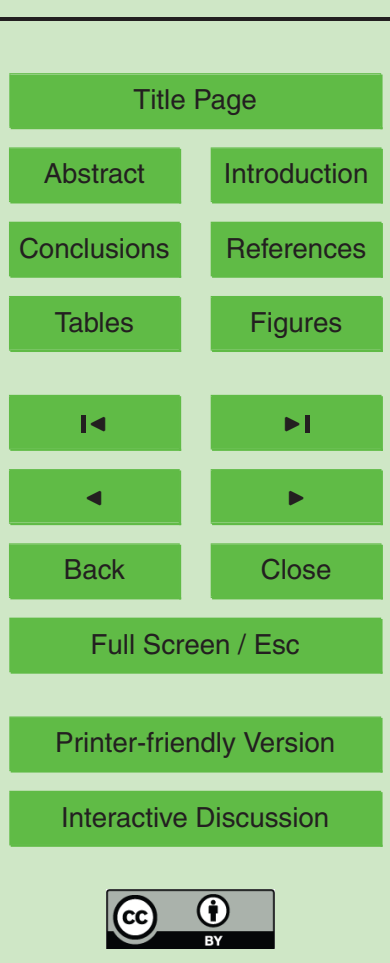


between drains that was affected by bromide application of about $60 \mathrm{~m}^{2}$. For considering the effects of areal rain and plot-scale irrigation on the field-scale drain discharge, two separately simulated drainage time series', one for irrigated (i.e., by applying rainfall and irrigation rates) and another for non-irrigated areas (i.e., by applying rainfall 5 only), were combined based on area-weighing procedures (Gerke et al., 2007). The procedure yields area-weighed curves of tile outflow and $\mathrm{Br}^{-}$effluent concentration that are representative for the $5000 \mathrm{~m}^{2}$ drained field (level A, Fig. 2).

As a quantitative comparison of simulated and measured effluent data, the model efficiency coefficient, $E$ ("Nash criterion"), was calculated (Nash and Sutcliffe, 1970) 10 as:

$$
E=1-\frac{\sum_{t=1}^{T}\left(X_{\mathrm{o}}-X_{\mathrm{m}}\right)^{2}}{\sum_{t=1}^{T}\left(X_{\mathrm{o}}-\overline{X_{\mathrm{o}}}\right)^{2}}
$$

where $X_{\mathrm{o}}$ is observed and $X_{\mathrm{m}}$ is simulated variable; $\bar{X}_{\mathrm{o}}$ is the mean value of observed variable.

\section{Results}

The results are focusing on the period 25-31 March 1997, that includes the irrigation and the following rain events (i.e., Days 97-103 after first $\mathrm{Br}$ application). The specific discharge curves demonstrate the relation between the plot-scale 2D-DPERM flow simulations and the field-scale aggregated curves that are comparable with data measured at the drain outlet (Fig. 4). The simulated discharge is slightly above and 20 nearly parallel to the data. While the peaks in response to irrigation and rain are similar, a systematic over-prediction of discharge indicates that the catchment boundaries are probably not completely impermeable as assumed in the simulations. The field-scale discharge curves (Fig. 4) also reflect the different reactions on either plot-scale irrigation (Days 97 and 98 ) or field-scale rain (Day 100). The rain produced a much stronger 5933
HESSD

8, 5917-5967, 2011

\section{Mass transfer effects in 2-D-DPERM modeling}

H. H. Gerke et al.

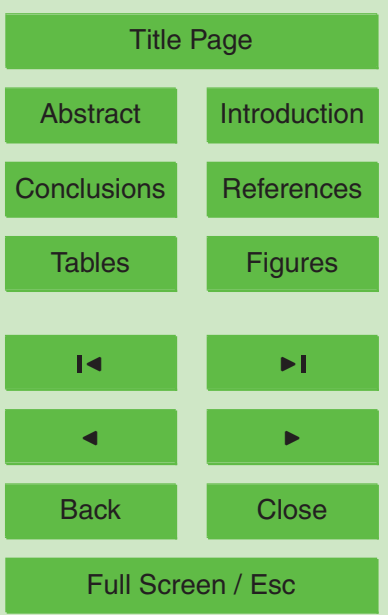

Printer-friendly Version

Interactive Discussion 
discharge signal than the local irrigation events because of the larger contribution to the catchments water balance. In contrast, the simulated plot-scale discharge curves (Fig. 4) reflect the effect of the irrigation procedure in more detail including peaks following individual 30-min irrigation intervals. The response of the specific discharge to 5 the second irrigation period (Day 98) is stronger than the response to the first irrigation and to the rain, an effect that can hardly be found for the field-scale discharge; note that no data are available for comparisons at the plot-scale. The small mismatch in the timing of drain discharge peaks between simulated and measured curves (Fig. 4) may be explained by effects of field-scale heterogeneity; the data are composed of contri10 butions from various regions of the drained catchment that could have responded at somewhat different times and rates.

Time series' of measured (data) and simulated (model) soil water pressure heads in $0.15 \mathrm{~m}$ depth and in $1 \mathrm{~m}$ and $3 \mathrm{~m}$ distance from the tile line reveal how soil hydraulic conditions are captured in the 2D-DPERM model (Fig. 5). The simulated curves for the SM domain represent the pore domain that is dominating water retention during infiltration-free periods. Note that we did not optimize the hydraulic parameters. Nevertheless, simulated and measured data match with respect to timing in response to the infiltration (Fig. 5); however, simulated curves are somewhat below the measured ones, and pressure head values are more slowly decreasing and without daily fluctuations at later times (i.e., after Day 103). The peak matching between simulated and measured pressure heads seems to be different for irrigation and rainfall periods. Irrigation including surface redistribution of infiltrating water between domains is better matched than infiltration during rain.

The bromide mass flux with the effluent at the drain outlet (Fig. 6a) reflects the different preferential leaching effects in response to irrigation and rain. During the first day's drain discharge peak, $\mathrm{Br}^{-}$concentrations in the effluent remain relatively small at the plot (Fig. 6b) and also at the field-scale (Fig. 6c); the effluent $\mathrm{Br}^{-}$concentrations at the field drain outlet peaked at the end of the second irrigation (Day 98). A smaller peak in measured effluent $\mathrm{Br}^{-}$concentrations was observed on Day 99 (Fig. 6c) following
HESSD

8, 5917-5967, 2011

\section{Mass transfer effects \\ in 2-D-DPERM modeling}

H. H. Gerke et al.

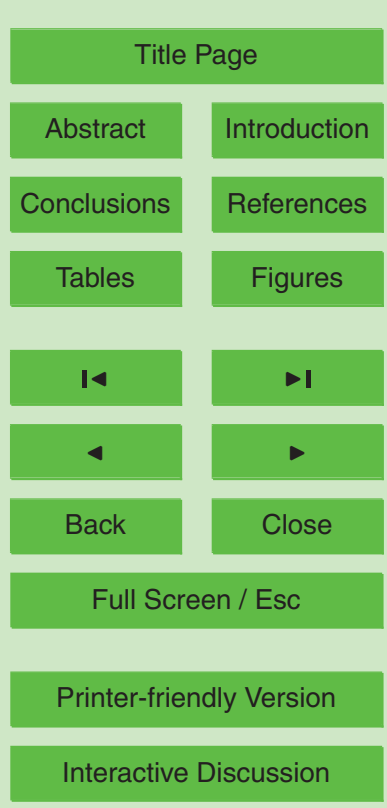


a smaller rain event; afterwards $\mathrm{Br}^{-}$concentrations (data) dropped due to dilution especially after the end of rain (Day 100) by discharge from the rest of the field. The fieldscale mass flux (Fig. 6a) is first reflecting the concentration increase during the second irrigation (Fig. 6c) and later the discharge peak (Fig. 4). The measured bromide mass

5 flux in the drain effluent compares best with simulated and field-scale extrapolated results (Fig. 6a) when assuming reduced values of the mass transfer rate coefficient $\alpha_{\text {ss }}$ (Table 2).

For the cumulative bromide mass leached with drain effluent (Fig. 7), the mass transfer scenario "2D-DPERM low" $\left(\alpha_{\text {ss }}=0.02\right.$ (topsoil) and 0.01 (subsoil)) is slightly closer 10 to the measured curve than the scenario "lowest" that assumes 10-times smaller transfer coefficients. The value of the Nash-Sutcliffe coefficient is highest for "2D-DPERM low", while the bromide mass difference between measured and simulated of $-27 \mathrm{~g}$ is smallest for "high" scenario (Table 3). When using larger values of the mass transfer coefficient (i.e., 2D-DPERM "high" and "highest"), the $\mathrm{Br}^{-}$mass flux peaks are overes15 timated during first and underestimated during second irrigation and the rain (Fig. 6a). The $\mathrm{Br}^{-}$concentrations in the effluent (plot-scale) are increasing during the second day of irrigation and dropping to a basis level during the rainfall event (Fig. 6b).

The 2D-DPERM simulations of the irrigated plot allow analyzing drain discharge (Fig. 8a) and $\mathrm{Br}^{-}$effluent concentrations (Fig. 8b) separately for the PF domain and 20 the SM domain. The curves indicate that most of the drain discharge comes from the PF domain; discharge from the SM domain reacts more slowly with the peak during the second irrigation day (Fig. 8a). Moreover, the 2D-DPERM simulations predict that the $\mathrm{Br}^{-}$concentration in the PF domain mainly controls composite mass flux. The $\mathrm{Br}^{-}$concentration in the SM domain effluent is decreasing during infiltration events (Fig. 8b); the $\mathrm{Br}^{-}$effluent concentration curves of the PF and SM domains are even oriented in opposite directions (as explained in Sect. 4.3).

The plot of cumulative water transfer integrated over the whole 2-D cross sections (Fig. 9) graphically displays the averaged dynamics of water exchange between the $\mathrm{SM}$ and PF domains. Positive rates or increasing cumulative values, indicating water
HESSD

8, 5917-5967, 2011

\section{Mass transfer effects in 2-D-DPERM modeling}

H. H. Gerke et al.

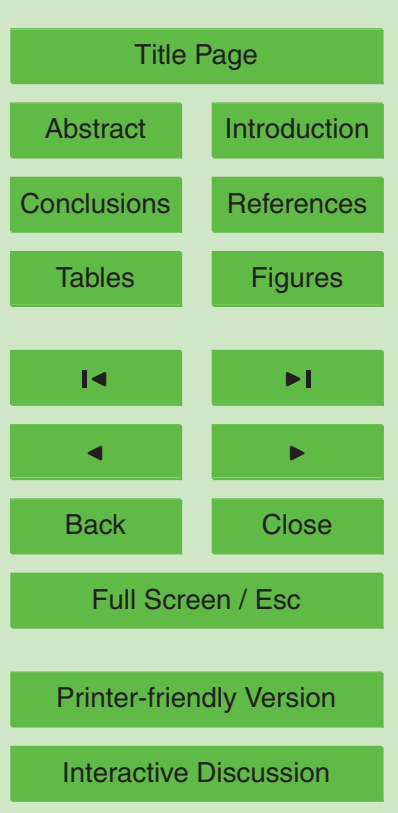

Interactive Discussion 
transfer from the PF to the SM domain, are reflecting two situations: (i) during redistribution of infiltration at the soil surface towards the PF domain and (ii) at the end of rain water infiltration (Day 100) when transfer from the highly saturated PF domain to the less saturated SM domain is continuing in the subsoil. For 2D-DPERM simulation 5 scenarios without including the irrigation events (Fig. 9), the cumulative water transfer is initially negative (SM $\rightarrow$ PF domain) since water is infiltrating proportionally in both domains at the soil surface and the less permeable SM-domain (as compared to the PF-domain) develops relatively higher water pressure heads; as for the scenario with irrigation, the water transfer direction reverses after the end of the rain (after Day 100) 10 as long as the PF domain pressure head increased faster than that of the SM domain. During other infiltration-free periods, transfer is directed from the SM domain to the PF domain at gradually decreasing rates (Fig. 9).

The water exchange mechanisms are further illustrated by 2-D cross-sectional pressure head and transfer distributions (Fig. 10) for two contrasting situations of (i) positive 15 water transfer from the PF to SM domain during the first irrigation event (Day 97.73) and (ii) negative transfer during rain (Day 100.125); times are indicated by vertical lines in Fig. 9. During irrigation (Fig. 10, left side), the PF domain (Fig. 10b) is almost completely saturated due to the additional domain-specific infiltration while the SM domain (Fig. 10a) is less saturated between about 30 and $80 \mathrm{~cm}$ soil depth. Water transfer rates are spatially variable within the flow domain because of the lateral flow towards the drain effect; the largest positive exchange rates are at the side opposite to the drain tile where the pressure differences are greatest (Fig. 10c). In contrast, the situation during the rain (Fig. 10, right side) indicates that the SM domain (Fig. 10d) is more rapidly wetting than the PF domain (Fig. 10e) especially near the surface. The spatial distribution of water exchange rates in the 2-D cross-section (Fig. 10f) reveals two regions with negative values, one is in the topsoil, with a tendency towards less negative values to the drain side, and the other region in the subsoil is following the water table (i.e., negative transfer, $\mathrm{SM} \rightarrow \mathrm{PF}$ domain); this is because the SM water table is higher than the one in the more permeable PF-domain.

\section{HESSD}

$8,5917-5967,2011$

\section{Mass transfer effects in 2-D-DPERM modeling}

H. H. Gerke et al.

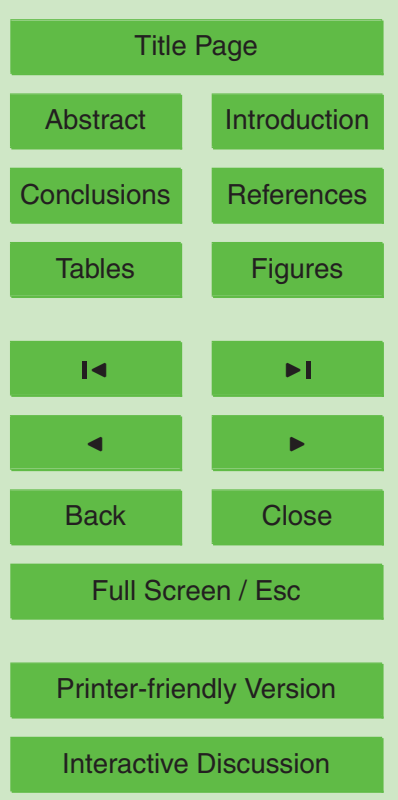


For the $\mathrm{Br}^{-}$mass transfer (Eq. 5) both "advective" (i.e., driven by water exchange, Eq. 2) and "diffusive" components (i.e., driven by local concentration difference between domains) react differently during irrigation or rain and for "low" and "high" mass transfer coefficients (Fig. 11). As for water (Fig. 11), positive rates indicate transfer 5 directed in the SM domain and negative rates a transfer to the PF domain. Since $\mathrm{Br}^{-}$is assumed to enter the soil only through the SM domain, the total cumulative transfer of $\mathrm{Br}^{-}$is generally negative for both scenarios, "high" and "low" (Fig. 11). Nevertheless, $\mathrm{Br}^{-}$transfer rate components can turn positive. For the scenario assuming "high", diffusive mass transfer becomes positive during the infiltration-free periods after irrigation 1 and rain events because only the "diffusive" transfer component (PF $\rightarrow$ SM domain) prevails. Obviously, the "advective" component, dominating during infiltration, is negative (Fig. 11); the transfer rates are larger for the rain than for the irrigation events. The "diffusive" transfer component is negative especially for "high" scenario during irrigation when solute-free water infiltrates into the PF domain. The "low" mass transfer scenario 15 predicts the largest overall $\mathrm{Br}^{-}$transfer from the $\mathrm{SM}$ domain to the $\mathrm{PF}$ domain (i.e., considering the sum of both "advective" and "diffusive" components).

A fraction of $555 \mathrm{~g}$ of the applied bromide $(4300 \mathrm{~g})$ was found in the drain effluent; the larger $\mathrm{Br}^{-}$mass is distributed as residual bromide in the soil. The 2-D spatial distributions of residual $\mathrm{Br}^{-}$concentration in the SM domain and the PF domain and of Mass transfer coefficients affect the spatial distribution of resident $\mathrm{Br}^{-}$concentrations in the SM domain (Fig. 12a) and the PF domain (Fig. 12b) and of the solute mass transfer (Fig. 12c), mainly in the subsoil below the $30-\mathrm{cm}$ application strip. The plots show the situation at the end of the rain (Day 101.125), comparable to 2-D water transfer distribution (Fig. 10 right). Bromide concentration plumes are laterally directed towards the drain. The centre of mass is residing in the topsoil of the SM domain for the "lowest" values of the exchange coefficient $\alpha_{\mathrm{ss}}$ (Fig. 12a). The $\mathrm{Br}^{-}$plume is more spread out with increasingly larger mass transfer scenarios. For the PF domain, the residual $\mathrm{Br}^{-}$ plume keeps a relatively similar shape with increasing mass transfer (Fig. 12b). For the

\section{HESSD}

$8,5917-5967,2011$

\section{Mass transfer effects in 2-D-DPERM modeling}

H. H. Gerke et al.

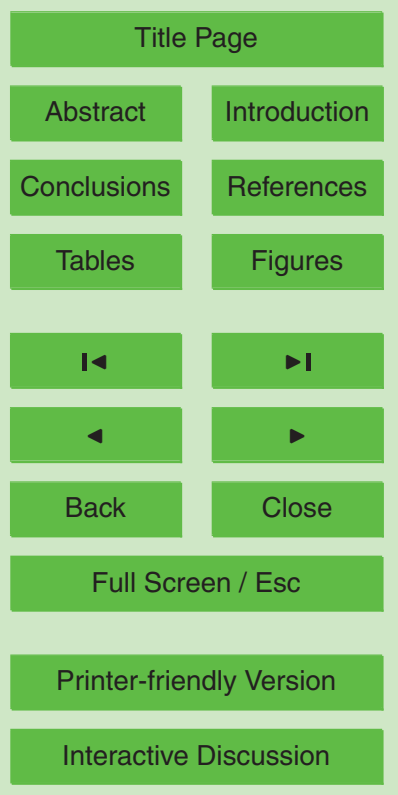

Interactive Discussion 
"low" and "lowest" scenarios, mass transfer is only negative (i.e., SM to PF domain) and restricted exclusively to the topsoil (Fig. 12c). Positive transfers (i.e., PF to SM domain) are obtained for the "high" and "highest" scenarios, however, only in the subsoil (i.e., transfer of preferentially transported $\mathrm{Br}^{-}$to the SM domain) and in the topsoil regions 5 outside the $30-\mathrm{cm}$ application strip (i.e., by lateral spreading).

A comparison of the cumulative water and solute mass transfer at time 97.73 days during irrigation shows that water transfer is positive (Fig. 9) while the cumulative $\mathrm{Br}^{-}$ transfer in the 2-D cross-section (for "high" scenario) is negative (Fig. 11), which appears to be counter intuitively. For explanation, the 2-D spatial distributions of water

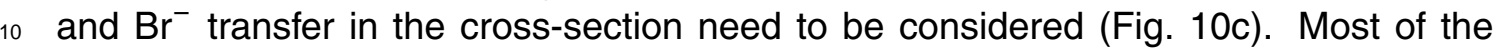
positive water transfer (i.e., PF to SM domain) is in the upper part of the subsoil (50 to $100 \mathrm{~cm}$ depth) during irrigation; while most of the negative $\mathrm{Br}^{-}$transfer (i.e., SM to PF domain) is in the topsoil (Gerke et al., 2007, Fig. 6) where the water transfer is also slightly negative (Fig. 10c). Furthermore, the positive water transfer region underneath the $\mathrm{Br}^{-}$application strip around $100 \mathrm{~cm}$ horizontal distance from the drain is smaller than in the soil regions further apart from the drain, and hence contributes relatively less to the cumulative mass transfer.

\section{Discussion}

\subsection{Effect of solute transfer components on leaching and residual bromide concentrations}

When considering "advective" and "diffusive" components of the cumulative $\mathrm{Br}^{-}$mass transfer integrated over the whole 2-D cross sections separately (Fig. 11), it appears that the differences in the effluent curves in comparison with data (Fig. 7) between higher and lower transfer scenarios are attributed almost entirely to the diffusive component. For the high transfer scenario (Fig. 11), the overall "diffusive" transfer shows a positive trend (i.e. PF to SM domain). However, also the "advective" component is
HESSD

$8,5917-5967,2011$

\section{Mass transfer effects in 2-D-DPERM modeling}

H. H. Gerke et al.

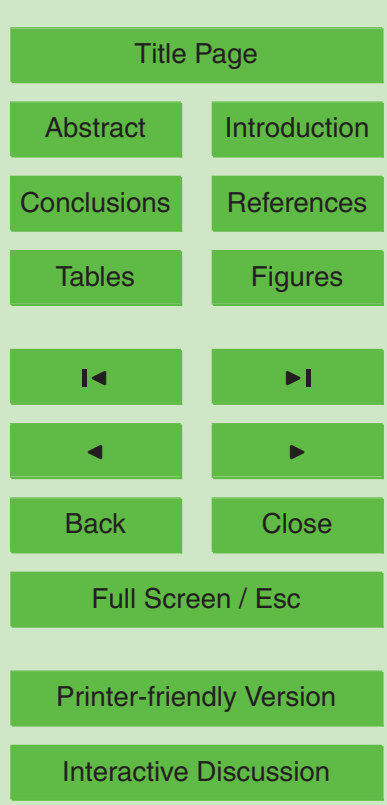


affected when changing the value of the "diffusive" transfer coefficient. In case of local non-equilibrium, any deviation in the spatial distribution of residual $\mathrm{Br}^{-}$in one domain modifies the "advective" transfer component in all consecutive steps. For the "diffusive" component, the explanation is different: The "higher" transfer scenarios allow more $\mathrm{Br}^{-}$

5 to be transferred to the PF domain according to the concentration differences during the preferential flow events (i.e., water infiltrating in the PF domain is assumed here free of bromide at the surface). The direction of mass transfer immediately reverses after the infiltration because the transfer in the topsoil ceases while mass transfer (i.e., PF to SM domain) in other parts of the soil may continue. Since the drained volume 10 of the PF domain under unsaturated conditions is small as compared to that of the SM domain, the solute mass remaining in PF domain is small such that the initial negative transfer is nearly balanced by positive transfer during infiltration free periods. During infiltration-free periods, the SM domain receives solutes from the PF domain all along the preferential transport plume.

15 For the "lower" transfer coefficients, effects are much smaller as described above for the "higher" scenarios. The relatively small "diffusive" transfer component limits first the transfer from the SM to PF domain in the topsoil and later the rate of "diffusive" backtransfer in the subsoil (i.e. PF to SM domain). For the PF domain (Fig. 12b), plumes that are generated entirely by mass transfer from the SM domain, are relatively similar because this transfer is mostly "advective" and less affected by values of $\alpha_{\text {ss }}$, except that the highest exchange coefficient scenario with the largest concentrations in the topsoil is reflecting a stronger tendency of local equilibration. In contrast, the differing 2-D spatial distribution of the $\mathrm{Br}^{-}$concentration plumes in the SM and PF domains for the scenario with the lowest exchange coefficient $\alpha_{\mathrm{ss}}$ (Fig. 12a, b), are reflecting the effect of local non-equilibrium in $\mathrm{Br}^{-}$concentrations between domains. Nevertheless, the $\mathrm{Br}^{-}$exchange (Fig. 12c) is qualitatively similar for all scenarios indicating a negative transfer in the topsoil (i.e., $\mathrm{SM} \rightarrow \mathrm{PF}$ domain) and a positive transfer in the subsoil (i.e., $\mathrm{PF} \rightarrow \mathrm{SM}$ domain). The larger transfer of $\mathrm{Br}^{-}$from the PF to the SM domain in the subsoil is the main reason why the peaks of the $\mathrm{Br}^{-}$effluent concentrations at later
HESSD

8, 5917-5967, 2011

\section{Mass transfer effects in 2-D-DPERM modeling}

H. H. Gerke et al.

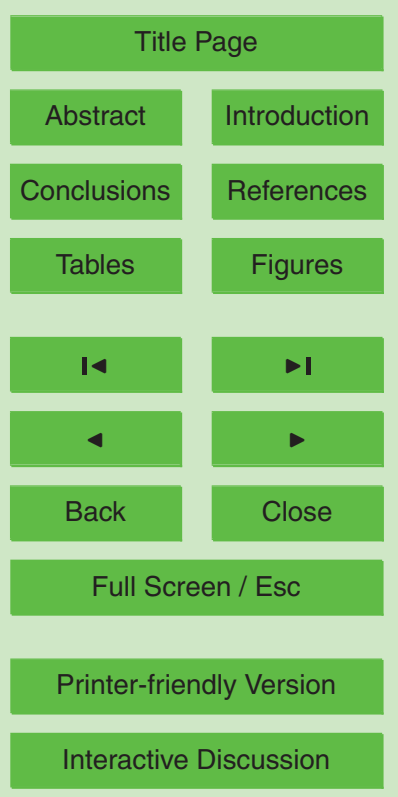


times (after Day 100) are smaller for higher values of the exchange coefficient $\alpha_{\text {ss }}$ (Fig. 6b). The $\mathrm{Br}^{-}$effluent concentration will, of course, gradually decrease for the "low" transfer scenario as well; however, much later as compared to "high" transfer scenarios. Note that the "highest" scenario, showed Br leached mass close to results 5 obtained with 2-D single domain simulations of this experiment (Gerke et al., 2007).

The conceptual framework of field-scale integrating local- and plot-scale flow and transport processes in the 2D-DPERM simulations across the whole subsurfacedrained catchment (Fig. 2) provides a quantitative comparison with experimental data of distributed $\mathrm{Br}^{-}$concentrations (cf., Gerke et al., 2007, Fig. 9) or pressure heads 10 (e.g., Fig. 5) obtained at the appropriate spatial scale. The 2D-DPERM simulations of residual $\mathrm{Br}^{-}$concentrations in the soil perpendicular to the tile line (Fig. 12) can directly be compared with soil trench data at the plot-scale thereby eliminating possible uncertainties (e.g., Jacobsen and Kjaer, 2007) between the averaged solute concentration measured in the drain effluent and the representative $\mathrm{Br}^{-}$concentrations in the soil

\subsection{Mass transfer and small-scale soil structure properties}

The 2D-DPERM model analyzes effects of local-scale soil structure properties on $\mathrm{Br}^{-}$ leaching at field-scale. The model allows for surface redistribution and subsurface local nonequilibrium in both pressure head and solute concentration between the two conceptual pore domains (Fig. 2d). The soil structural properties are represented in form of effective transfer term parameters. Water transfer effects, analyzed extensively before in 1-D and 2-D (e.g., Gerke and Köhne, 2004; Dusek et al., 2008), are complemented here in the variations of the solute mass transfer coefficient $\alpha_{\text {ss }}$. Conceptually, this parameter can represent soil structural properties along preferential flow paths such as 25 clay coating with a very fine porosity that limits the movement of water and the diffusion of solutes across that local interface.

The exchange coefficients are characterizing the properties at the interface between the PF and SM domains such as density, pore size distribution, clay and organic matter
HESSD

8, 5917-5967, 2011

\section{Mass transfer effects in 2-D-DPERM modeling}

H. H. Gerke et al.

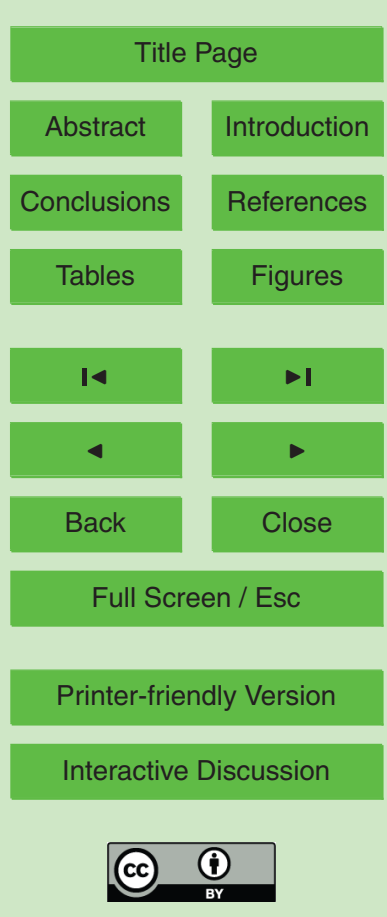


content and composition, and wettability among other properties which are lumped together with shape and form effects of the interface. Measurement of mass exchange between macropores and SM remains a challenge for preferential flow research (Allaire et al., 2009). The soil structure is changing with depth in many soils, for instance, 5 by vertically decreasing macropore fractions (e.g., Haws and Rao, 2004). The same authors assume $\alpha_{\mathrm{d}}$ values for "diffusive" mass transfer of $0.02 \mathrm{~h}^{-1}$ and $0.015 \mathrm{~h}^{-1}$ with $\theta_{\mathrm{f}}=0.1$ and 0.043 ; the value corresponds to our $\alpha_{\mathrm{ss}}$ at saturation of $0.48 \mathrm{~d}^{-1}$ und $0.36 \mathrm{~d}^{-1}$. Ritter et al. (2005) fitted similar values for mobile-immobile transport modeling of soil columns. Köhne et al. (2002a) determined a diffusive reduction by aggregate coating of 30-times for $\mathrm{Br}^{-}$at saturation. Most useful macropore parameters for predicting flow and transport under saturated condition in structured soils included macroporosity, path number, hydraulic radius, and macropore angle (Luo et al., 2010) for the soil column experiments. We neglect here that the density of the fissure network is decreasing with depth; this effect can be considered by changing the volumetric 15 weighing coefficient $w_{\mathrm{f}}$. At the Bokhorst site, the soil in the upper $1 \mathrm{~m}$ depth is not much different with respect to macroscopically visible structure while other properties remain unknown.

Matching physical parameters with the structural development of soils to predict the likelihood of preferential flow for soil horizons or pedons could be included in the modeling. Soil structural features include aggregate or biopore geometry, hydraulic and transport properties of aggregates and biopores, or properties of burrow walls or clayorganic coatings (Jarvis, 2007). Suggestions for quantification of the relation between soil structural development and preferential flow (e.g., Vervoort et al., 1999) relate soil structural information and dye staining patterns with parameters such as dispersivity,

hydraulic conductivity, mobile water contents, and exchange coefficients (e.g., Haws and Rao, 2004; Merdun and Quisenberry, 2004). The solute mass transfer rate coefficients obtained from fitting breakthrough curves were found to differ significantly between pedons and were reduced in the Bt horizon (Shaw et al., 2000); compared with the "diffuse" component, these values were in the range of the "low" and lowest'

HESSD

8, 5917-5967, 2011

\section{Mass transfer effects in 2-D-DPERM modeling}

H. H. Gerke et al.

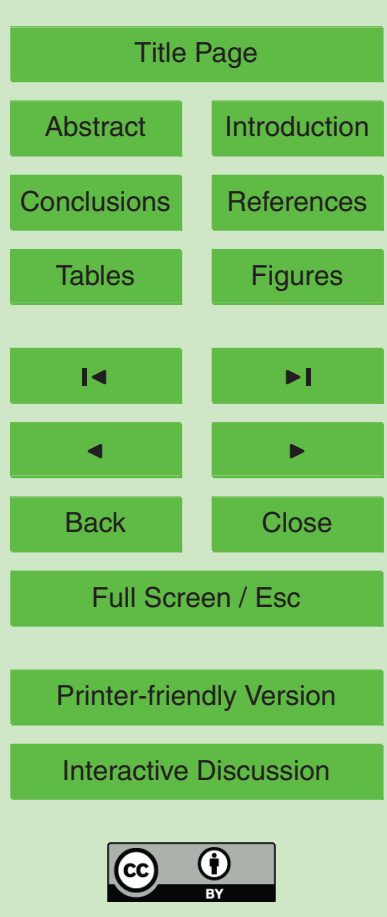


scenarios of this study. Low values of the mass transfer coefficients, equivalent to $\alpha_{\text {ss }}$, at saturation of about $1.6 \mathrm{~d}^{-1}$ and $0.6 \mathrm{~d}^{-1}$ for subsoil horizons were reported (e.g., Ersahin et al., 2002) but reductions can also occur in the topsoil; for instance, when compacted clods are left by tillage operations (Coquet et al., 2005) or the compacted 5 zones divert water and solute movement around them. A conceptual classifies soil horizons into soil susceptibility classes for macropore flow on the basis of available site and soil factors (Jarvis et al., 2009).

\subsection{Domain-specific discharge and effluent concentrations}

While the increase in effluent concentrations for the PF domain (Fig. 8b) reflects preferential $\mathrm{Br}^{-}$transport in the soil underneath the $0.3 \mathrm{~m}$ wide application strip, the decrease for the SM domain concentrations can be explained by the effects of the water movement in the whole 2-D vertical cross-section. Here, water table increase during irrigation and rain stimulates lateral movement of solute-free water towards the drain tile where it dilutes the $\mathrm{Br}^{-}$plume. Afterwards, during declining water table, the vertical transport component and increasing mass transfer allow the SM domain effluent concentrations to rise again. A water table increase is particularly leading to larger non-equilibrium conditions in $\mathrm{Br}^{-}$effluent concentrations between $\mathrm{SM}$ and PF domain because mass transfer is limited in case of saturation to the "diffusive" component (Eq. 5). Furthermore, the lateral groundwater movement is initially pushing the bromide plume aside.

\subsection{Drain discharge patterns}

The drain effluent triggered by PF is typically characterized by relatively large but shortlived solute concentration peaks and a reversed peak dynamic with largest concentrations during first drainage event after application (Kladivko et al., 2001). Such patterns have been observed for tile-drained experimental sites where soils developed from glacial till sediments (Wichtmann et al., 1998; Villholth et al., 1998; Jaynes et al.,
HESSD

8, 5917-5967, 2011

\section{Mass transfer effects in 2-D-DPERM modeling}

H. H. Gerke et al.

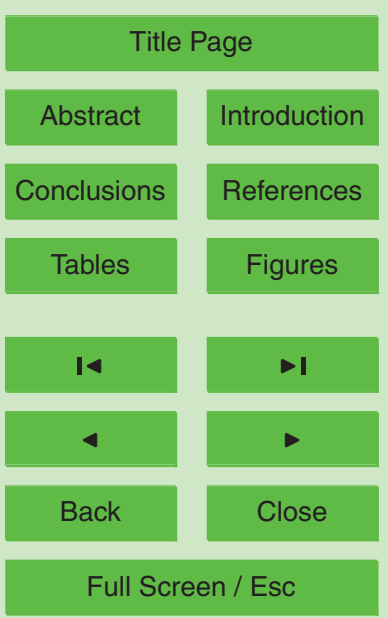

Printer-friendly Version

Interactive Discussion 
2001). For the field-scale bromide mass flux in the drain effluent (Fig. 6); however, the bromide peak in response to the second irrigation is higher than the response to the first irrigation. The uncommon PF patterns of $\mathrm{Br}^{-}$concentration in tile effluent can be described with a combination of two local-scale effects (cf., Gerke et al., 2007): 5 the SM domain infiltration and a reduced solute mass transfer. The relevance of the first local effect, the redistribution of infiltrating water at the soil surface has previously been derived from observations of the distribution of infiltrating water in small-scale dye experiments. For instance, Neurath et al. (2005) found that PF flow paths established already in the upper $3 \mathrm{~cm}$ soil. The second local effect is controlled mainly by "diffusive" 10 component of the solute transfer in highly water-saturated subsoil.

The simulated peak in response to the rain (Day 100) comes a bit too late while the peaks in response to the irrigation events are fully matching (Fig. 6). Since bromide effluent can only come from the irrigated plot, the timing difference during rain must be related to heterogeneity in drain discharge contributions from various parts of the entire catchment. A faster ponding at the surface of the SM domain and an earlier surface water redistribution into the PF domain would increase the response time for $\mathrm{Br}^{-}$leaching to rain in a similar way as for the irrigation. The mismatch in the response to the smaller rainfall event on Day 99 (Fig. 6) may similarly be explained by the lack of surface redistribution between domains in the simulations. Overall, the stronger mass transfer reductions (e.g., 2D-DPERM low, Fig. 6) match the data most closely. The overestimated bromide fluxes during the declining branches of the curves (Fig. 6) indicate that solute mass transfer is probably more complex or more dynamic as assumed here. Transfer may be larger after cessation of infiltration such that more $\mathrm{Br}^{-}$is transferred to the PF domain; alternatively, transfer in the subsoil may be reduced such that 25 more $\mathrm{Br}^{-}$remains in the PF domain. Nevertheless, both the surface boundary influx conditions and the mass transfer reductions as shown here, can affect $\mathrm{Br}^{-}$leaching at the field-scale.

Vervoort et al. (1999) postulated that local-scale PF processes highly influence field-scale solute transport; hence local effects are not dampened at the field-scale.
HESSD

8, 5917-5967, 2011

\section{Mass transfer effects in 2-D-DPERM modeling}

H. H. Gerke et al.

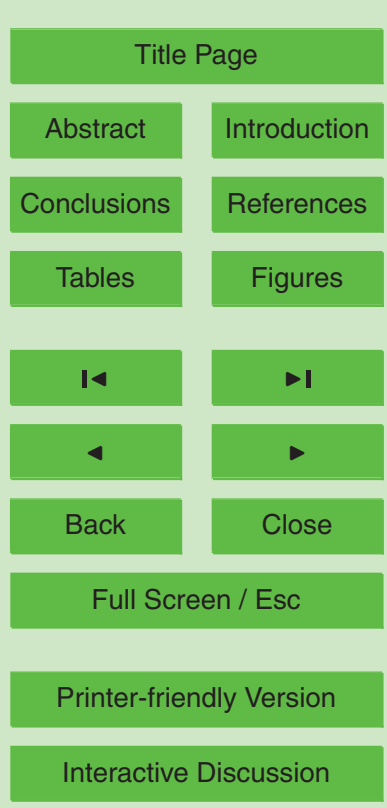


Reasons for small-scale variations of soil structural properties are manifold (e.g., shrinkage, biological activity, movement of colloids, root exudates). All these can be affected by land use and soil management practices such as crop rotations and field water management (e.g., drainage or irrigation). Thus, in particular for those arable

5 field sites and catchment locations where non-equilibrium type of preferential flow and transport processes occur, there is a link between soil management affecting smallscale soil structure properties and the hydrology. As a consequence, analyses and descriptions of field-scale hydrological behavior require appropriate considerations of smaller-scale effects of soil structure leading to preferential flow.

\section{Conclusions}

This study analyzes and reviews small-scale soil structure effects as reflected in the mass transfer terms of the 2-D dual-permeability model (DPERM) on water and $\mathrm{Br}^{-}$ movement towards subsurface drains at field-scale. For a previously evaluated scenario (i.e., realistic irrigation rates, flux solute $\mathrm{BC}$, and SM domain of solute application) 15 that best approximated a $\mathrm{Br}^{-}$field tracer irrigation experiment, the sensitivity analysis has been complemented with respect to the coefficient $\alpha_{\mathrm{ss}}$, of solute mass transfer term parameter. The 2D-DPERM modeling of flow and transport in $5.9 \mathrm{~m} \times 2.0 \mathrm{~m}$ vertical cross sections and a plot- and field-scale weighing procedure (i.e., $60 \mathrm{~m}^{2}$ plot vs. $5000 \mathrm{~m}^{2}$ field) describes the interplay between two local effects, (i) the redistribution at 20 the soil surface when the SM domain starts ponding, and (ii) the inter-domain mass transfer in a structured soil where exchange is reduced due to coating effects.

The simulations reveal that a reduced "diffusive" component in the transfer term can be a dominant factor for controlling preferential solute leaching and nonequilibrium in solute concentration between domains. The scenario based on the lower values of the rate coefficients allowed a better match of the bromide mass flow observed in the tile drain discharge. The results give evidence that small-scale structural effects of macropore coatings - conceptualized as changes in rate coefficients - can have a clear

HESSD

8, 5917-5967, 2011

\section{Mass transfer effects in 2-D-DPERM modeling}

H. H. Gerke et al.

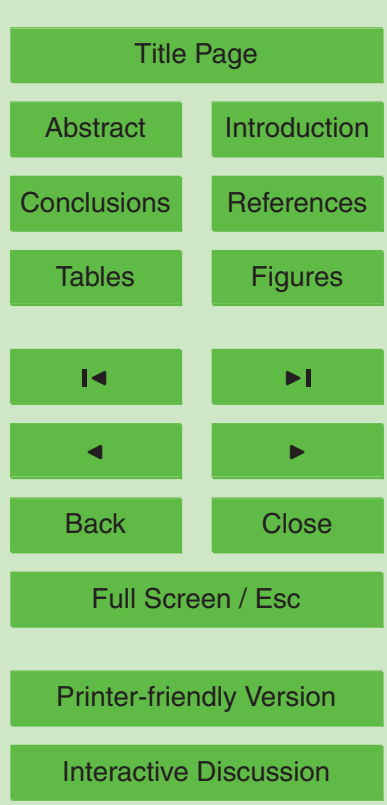

Interactive Discussion 
effect and are needed for understanding preferential flow and transport in arable fields with subsurface drains. Since soil structure-related local properties are depending also on soil and crop management, the susceptibility of a soil to PF can be influenced as well.

$5 \quad$ With this analysis we cross several spatial scales in order to analyze how local mass transfer (i.e., representing soil structure effects or properties that exist at the mm-scale) can possibly affect the drain discharge and effluent concentrations (i.e., representing an integrated signal at the field-scale). The comparisons between macroscopic scale DPERM simulations of flow and transport in a 2-D vertical cross-section and the ten10 siometer data and residual $\mathrm{Br}$ concentrations indicate that simulations include realistically most relevant processes at an intermediate plot-scale; the match of drain discharge and effluent concentrations indicate valid assumptions at the drained catchment scale. The simulation results suggest that local soil structure-related mass transfer parameters are sensitive as in the 1-D model but more complex for the plot-scale and still significant at the field-scale. For the conditions of nonequilibrium-type of PF of this experiment, structural effects at the soil surface (i.e., domain-redistribution of infiltrating water) and in the soil profile (i.e., reductions of mass transfer between pore domains) will not eventually average out when increasing scales or by water table fluctuations. The study may provide deeper understanding that may lead to adapted parameter estimation schemes and novel experiments for parameter determination. Where water and solutes enter the soil and exchange has not sufficiently been observed in field experiments and poses a yet largely open problem.

Acknowledgement. We thank the Ministry of Education of the Czech Republic for financial support (MSM 6840770002), the German Federal Ministry of Food, Agriculture, and Consumer

\section{HESSD}

$8,5917-5967,2011$

\section{Mass transfer effects in 2-D-DPERM modeling}

H. H. Gerke et al.

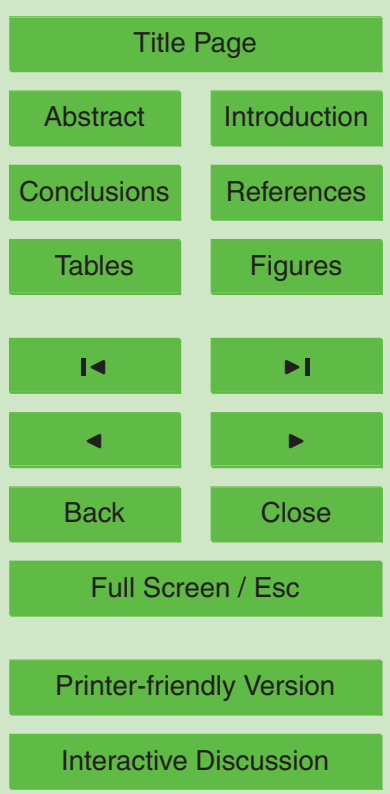




\section{References}

Akay, O. and Fox, G. A.: Experimental investigation of direct connectivity between macropores and subsurface drains during infiltration, Soil Sci. Soc. Am. J., 71(5), 1600-1606, 2007.

Akay, O., Fox, G. A., and Simunek, J.: Numerical simulation of flow dynamics during macroporesubsurface drain interactions using HYDRUS, Vadose Zone J., 7(3), 909-918, 2008.

Allaire, S. E., Roulier, S., and Cessna, A. J.: Quantifying preferential flow in soils: a review of different techniques, J. Hydrol., 378, 179-204, 2009.

Bear, J.: Dynamics of Fluids in Porous Media, American Elsevier, New York, 1972.

Berkowitz, B.: Characterizing flow and transport in fractured geological media: a review, Adv.

10 Water Resour., 25(8-12), 861-884, 2002.

Boivin, A., Šimùnek, J., Schiavon, M., and van Genuchten, M. T.: Comparison of pesticide transport processes in three tile-drained field soils using HYDRUS-2D, Vadose Zone J., 5, 838-849, 2006.

Brown, C. D. and van Beinum, W.: Pesticide transport via sub-surface drains in Europe, Environ. Poll., 157(12), 3314-3324, 2009.

Bundt, M., Jaggi, M., Blaser, P., Siegwolf, R., and Hagedorn, F.: Carbon and nitrogen dynamics in preferential flow paths and matrix of a forest soil, Soil Sci. Soc. Am. J., 65, 1529-1538, 2001.

Coquet, Y., Coutadeur, C., Labat, C., Vachier, P., van Genuchten, T., Roger-Estrade, J., and Simunek, J.: Water and solute transport in a cultivated silt loam soil: 1. field observations, Vadose Zone J., 4, 573-586, 2005.

Di Pietro, L., Ruy, S., and Capowiez, Y.: Predicting preferential water flow in soils by travelingdispersive waves, J. Hydrol., 278, 64-75, 2003.

Durner, W.: Predicting the unsaturated hydraulic conductivity using multi-porosity water retention curves, in: SHYPFIT, User's Manual, Research Report 93.11, Soil Physics, edited by: van Genuchten, M. T., Leij, F. J., and Durner, W., ITOE, ETH Zürich, Zürich, 1993.

Durner, W.: Hydraulic conductivity estimation for soils with heterogeneous pore structure, Water Resour. Res., 30, 211-233, 1994.

Dusek, J., Gerke, H. H., and Vogel, T.: Surface boundary conditions in 2-D dual-permeability modeling of tile drain bromide leaching, Vadose Zone J., 7, 1241-1255, 2008.

Dusek, J., Vogel, T., Lichner, L., and Cipakova, A.: Short-term transport of cadmium during a heavy-rain event simulated by a dual-continuum approach, J. Plant Nutr. Soil Sci., 173,
HESSD

8, 5917-5967, 2011

\section{Mass transfer effects in 2-D-DPERM modeling}

H. H. Gerke et al.

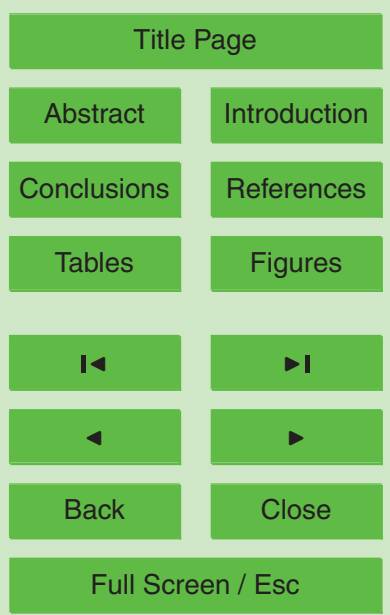

Printer-friendly Version

Interactive Discussion 
536-547, 2010.

Ebel, B. A., Mirus, B. B., Heppner, C. S., VanderKwaak, J. E., and Loague, K.: First-order exchange coefficient coupling for simulating surface water-groundwater interactions: parameter sensitivity and consistency with a physics-based approach, Hydrol. Proces., 23, 1949-1959, 2009.

Ellerbrock, R. H. and Gerke, H. H.: Characterizing organic matter of soil aggregate coatings and biopores by Fourier transform infrared spectroscopy, Eur. J. Soil Sci., 55, 219-228, 2004.

Ellerbrock R. H., Gerke, H. H., and Böhm, C.: In situ characterization of soil organic matter on surfaces of preferential flow paths using DRIFT spectroscopy, Soil Sci. Soc. Am. J., 73, $10 \quad$ 531-540, 2009.

Ersahin, S., Papendick, R. I., Smith, J. L., Keller, C. K., and Manoranjan, V. S.: Macropore transport of bromide as influenced by soil structure differences, Geoderma, 108, 207-223, 2002.

FAO: World Reference Base for Soil Resources. ISSS-ISRIC-FAO, World Soil Resources Report No. 84, FAO, Rome, 1998.

Feddes, R. A., Kowalik, P. J., and Zaradny, H.: Simulation of field water use and crop yield, Simulation Monographs, PUDOC, Wageningen, The Netherlands, 1978.

Flury, M., Flühler, H., Jury, W. A., and Leuenberger, J.: Susceptibility of soils to preferential flow of water: a field study, Water Resour. Res., 30, 1945-1954, 1994.

20 Fortin, J., Gagnon-Bertrand, E., Vézina, L., Rompré, M.: Preferential bromide and pesticide movement to tile drains under different cropping practices, J. Environ. Qual., 31, 1940-1952, 2002.

Gärdenäs, A. I., Šimùnek, J., Jarvis, N., and van Genuchten, M. T.: Two-dimensional modelling of preferential water flow and pesticide transport from a tile-drained field, J. Hydrol., 329, $25 \quad 647-660,2006$.

Gaur, A., Horton, R., Jaynes, D. B., and Baker, J. L.: Measured and predicted solute transport in a tile drained field, Soil Sci. Soc. Am. J., 70(3), 872-881, 2006.

Gentry, L. E., David, M. B., Royer, T. V., Mitchell, C. A., and Starks, K. M.: Phosphorus transport pathways to streams in tile-drained agricultural watersheds, J. Environ. Qual., 36(2), 408415, 2007.

Gerke, H. H.: Review article: Preferential flow descriptions for structured soils, J. Plant Nutr. Soil Sci., 169, 382-400, 2006.

Gerke, H. H. and van Genuchten, M. T.: A dual-porosity model for simulating the preferential
HESSD

8, 5917-5967, 2011

\section{Mass transfer effects in 2-D-DPERM modeling}

H. H. Gerke et al.

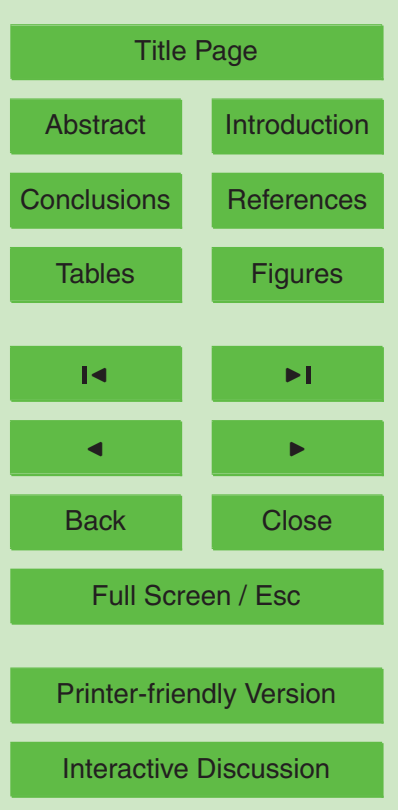


movement of water and solutes in structured porous media, Water Resour. Res., 29, 305319, 1993a.

Gerke, H. H. and van Genuchten, M. T.: Evaluation of a first-order water transfer term for variably saturated dual-porosity flow models, Water Resour. Res., 29, 1225-1238, 1993b.

5 Gerke, H. H. and van Genuchten, M. T.: Macroscopic representation of structural geometry for simulating water and solute movement in dual-porosity media, Adv. Water Resour., 19, 343-357, 1996.

Gerke, H. H. and Köhne, J. M.: Estimating hydraulic properties of soil aggregate skins from sorptivity and water retention, Soil Sci. Soc. Am. J., 66, 26-36, 2002.

10 Gerke, H. H. and Köhne, J. M.: Dual-permeability modeling of preferential bromide leaching from a tile drained glacial till agricultural field, J. Hydrol., 289, 239-257, 2004.

Gerke, H. H., Dušek, J., Vogel, T., and Köhne, J. M.: Two-dimensional dual-permeability analyses of a bromide tracer experiment on a tile-drained field, Vadose Zone J., 6, 651-667, 2007.

15 Gerke, H. H., Germann, P., and Nieber, J.: Preferential and unstable flow: from the pore to the catchment scale, Vadose Zone J., 9, 207-212, 2010.

Hansen, H. C. B., Jensen, M. B., and Magid, J.: Phosphate sorption to matrix and fracture wall materials in a Glossaqualf, Geoderma, 90, 243-261, 1999.

Haws, N. W. and Rao, P. S. C.: The effect of vertically decreasing macropore fractions on simulations of non-equilibrium solute transport, Vadose Zone J., 3, 1300-1308, 2004.

Haws, N. W., Rao, P. S. C., Šimùnek, J., and Poyer, I. C.: Single-porosity and dual-porosity modeling of water flow and solute transport in subsurface-drained fields using effective fieldscale parameters, J. Hydrol., 313, 257-273, 2005.

Hincapie, I. and Germann, P.: Gravity-driven viscous flow in sand boxes assessed with neutron radiography, Vadose Zone J., 8, 891-901, 2009.

Jacobsen, $\mathrm{O}$. $\mathrm{H}$. and Kjaer, J.: Is tile drainage water representative of root zone leaching of pesticides?, Pest Manag. Sci., 63, 417-428, 2007.

Jarvis, N. J.: A review of non-equilibrium water flow and solute transport in soil macropores: principles, controlling factors and consequences for water quality, Eur. J. Soil Sci., 58, 523546, 2007.

Jarvis, N. J., Moeys, J., Hollis, J. M., Reichenberger, S., Lindahl, A. M. L., and Dubus, I. G.: A conceptual model of soil susceptibility to macropore flow, Vadose Zone J., 8, 902-910, 2009.

\section{HESSD}

8, 5917-5967, 2011

\section{Mass transfer effects in 2-D-DPERM modeling}

H. H. Gerke et al.

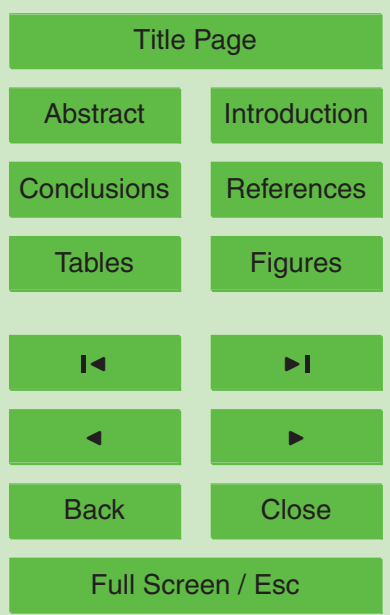

Printer-friendly Version

Interactive Discussion 
Jaynes, D. B., Ahmed, S. I., Kung, K.-J. S., and Kanwar, R. S.: Temporal dynamics of preferential flow to a subsurface drain, Soil Sci. Soc. Am. J., 65, 1368-1376, 2001.

de Jonge, V. N., Elliott, M., and Orive, E.: Causes, historical development, effects and future challenges of a common environmental problem: eutrophication, Hydrobiologia, 475(1), 119, 2002.

Kladivko, E. J., Brown, L. C., and Baker, J. L.: Pesticide transport to subsurface tile drains in humid regions of North America, Crit. Rev. Environ. Sci. Technol., 31, 1-62, 2001.

Klaus, J. and Zehe, E.: Modelling rapid flow response of a tile-drained field site using a 2-D physically based model: assessment of "equifinal" model setups, Hydrol. Proces., 24, 15951609, 2010.

Klaus, J. and Zehe, E.: A novel explicit approach to model bromide and pesticide transport in soils containing macropores, Hydrol. Earth Syst. Sci. Discuss., 8, 991-1029, doi:10.5194/hessd-8-991-2011, 2011.

Köhne, J. M.: Analyse präferentiellen Wasserflusses und Stofftransports in strukturierten 15 Böden mit Hilfe eines Dual-Porositätsmodells, Ph.D. diss. (In German, with English summary), in: Schriftenreihe Inst. Water Management and Landscape Ecology 30, edited by: Roweck, H. and Lennartz, B., Christian-Albrechts-Univ., Kiel, Germany, 1999.

Köhne, J. M. and Gerke, H. H.: Spatial and temporal dynamics of preferential tracer movement towards a tile drain, Vadose Zone J., 4, 79-88, 2005.

20 Köhne, J. M., Gerke, H. H., and Köhne, S.: Effective diffusion coefficients of soil aggregates with surface skins, Soil Sci. Soc. Am. J., 66, 1430-1438, 2002a.

Köhne, J. M., Köhne, S., and Gerke, H. H.: Estimating the hydraulic functions of dual-permeability models from bulk soil data, Water Resour. Res., 38, 1121, doi:10.1029/2001WR000492, 2002b.

Köhne, S., Lennartz, B., Köhne, J. M., and Šimùnek, J.: Bromide transport at a tile-drained field site: experiment, and one- and two-dimensional equilibrium and non-equilibrium numerical modeling, J. Hydrol., 321, 390-408, 2006.

Kohler, A., Abbaspour, K. C., Fritsch, M., van Genuchten, M. T., and Schulin, R.: Simulating unsaturated flow and transport in a macroporous soil to tile drains subject to an entrance head: model development and preliminary evaluation, J. Hydrol., 254, 67-81, 2001.

Kohler, A., Abbaspour, K. C., Fritsch, M., and Schulin, R.: Using simple bucket models to analyze solute export to subsurface drains by preferential flow, Vadose Zone J., 2, 68-75, 2003.

\section{HESSD}

8, 5917-5967, 2011

\section{Mass transfer effects in 2-D-DPERM modeling}

H. H. Gerke et al.

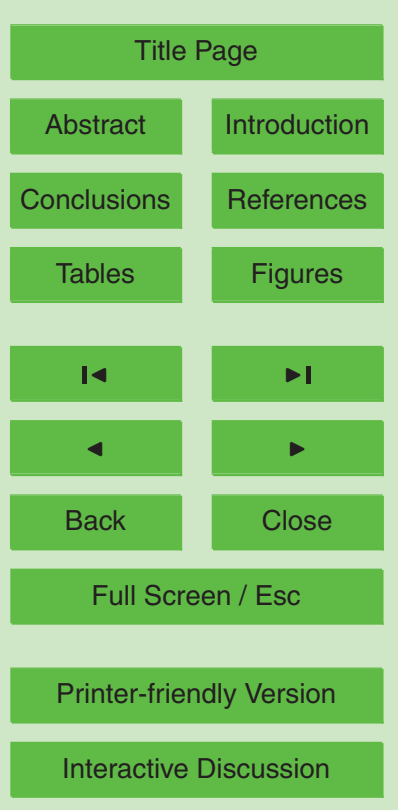


Kohler, A., Abbaspour, K. C., Fritsch, M., and Schulin, R.: Solute recycling by crops and leaching in a drained arable soil, Eur. J. Soil Sci., 56(2), 145-153, 2005.

Larsbo, M., Roulier, S., Semo, F., Kasteel, R., and Jarvis, N.: An improved dual-permeability model of water flow and solute transport in the vadose zone, Vadose Zone J., 4, 398-406, 52005.

Larsson, M. H. and Jarvis, N. J.: Evaluation of a dual-porosity model to predict field-scale solute transport in a macroporous soil, J. Hydrol., 215, 153-171, 1999.

Lennartz, B., Michaelsen, J., Wichtmann, W., and Widmoser, P.: Time variance analysis of preferential solute movement at a tile-drained field site, Soil Sci. Soc. Am. J., 63, 39-47, 101999.

Leue, M., Ellerbrock, R. H., and Gerke, H. H.: DRIFT mapping of organic matter composition at intact soil aggregate surfaces, Vadose Zone J., 9, 317-324, 2010.

Li, H., Sivapalan, M., Tian, F., and Liu, D.: Water and nutrient balances in a large tile-drained agricultural catchment: a distributed modeling study, Hydrol. Earth Syst. Sci., 14, 225915 2275, doi:10.5194/hess-14-2259-2010, 2010.

Luo, L. F., Lin, H., and Schmidt, J.: Quantitative relationships between soil macropore characteristics and preferential flow and transport, Soil Sci. Soc. Am. J., 74, 1929-1937, 2010.

Mallawatantri, A. P., McConkey, B. G., and Mulla, D. J.: Characterization of pesticide sorption and degradation in macropore linings and soil horizons of Thatuna silt loam, J. Environ.

20 Qual., 25, 227-235, 1996.

Merdun, H. and Quisenberry, V. L.: Relating model parameters to basic soil properties, Austr. J. Soil Res., 42, 841-849, 2004.

Millington, R. J. and Quirk, J. P.: Permeability of porous soils, Trans. Faraday Soc., 57, 12001207, 1961.

Nash, J. E. and Sutcliffe, J. V.: River flow forecasting through conceptual models part I: a discussion of principles, J. Hydrol., 10, 282-290, 1970.

Neurath, S. K., Sadeghi, A. M., Shirmohammadi, A., Torrents, A., and Sefton, K. A.: Sensitivity of atrazine partition coefficient on pesticide root zone model prediction of soil's atrazine residue distribution within the crop root zone, Soil Sci., 172, 42-54, 2007.

so Nielsen, M. H., Styczen, M., Ernstsen, V., Petersen, C. T., and Hansen, S.: Field study of preferential flow pathways in and between drain trenches, Vadose Zone J., 9, 1073-1079, 2010.

Nielsen, M. H., Styczen, M., Ernstsen, V., Petersen, C. T., and Hansen, S.: Distribution of bro-

\section{HESSD}

8, 5917-5967, 2011

\section{Mass transfer effects in 2-D-DPERM modeling}

H. H. Gerke et al.

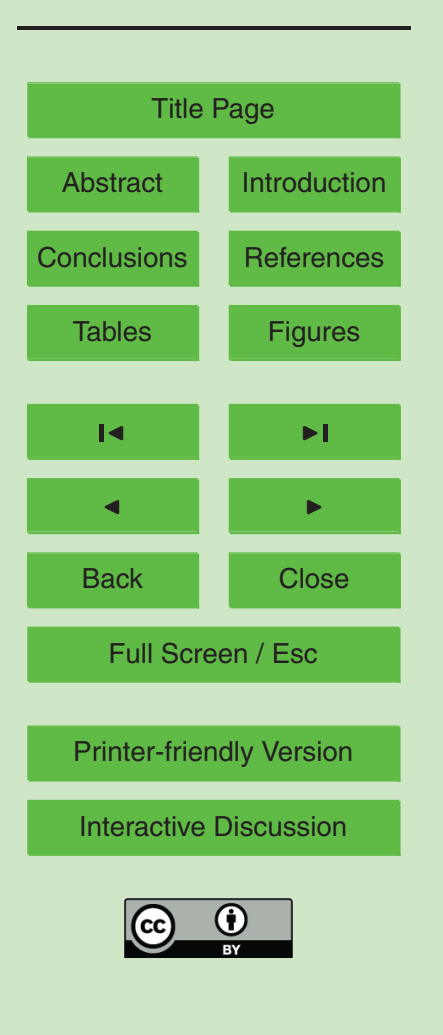


mide and microspheres along macropores in and between drain trenches, Vadose Zone J., 10(1), 345-353, 2011.

Nimmo, J. R.: Theory for source-responsive and free-surface film modeling of unsaturated flow, Vadose Zone J., 9, 295-306, 2010.

5 Ray, C., Vogel, T., and Dusek, J.: Modeling depth-variant and domain-specific sorption and biodegradation in dual-permeability media, J. Cont. Hydrol., 70, 63-87, 2004.

Richard, T. L. and Steenhuis, T. S.: Tile drain sampling of preferential flow on a field-scale, J. Contam. Hydrol., 3, 307-325, 1988.

Ritter, A., Muñoz-Carpena, R., Regalado, C. M., Javaux, M., and Vanclooster, M.: Using TDR and inverse modeling to characterize solute transport in a layered agricultural volcanic soil, Vadose Zone J., 4, 300-309, 2005.

Šimůnek, J., Jarvis, N. J., van Genuchten, M. T., and Gärdenäs, A.: Review and comparison of models for describing nonequilibrium and preferential flow and transport in the vadose zone, J. Hydrol., 272, 14-35, 2003.

15 Shaw, J. N., West, L. T., Radcliffe, D. E., and Bosch, D. D.: Preferential flow and pedotransfer functions for transport properties in sandy Kandiudults, Soil Sci. Soc. Am. J., 64, 670-678, 2000.

Shipitalo, M. J., Nuutinen, V., and Butt, K. R.: Interaction of earthworm burrows and cracks in a clayey, subsurface-drained, soil, Appl. Soil Ecol., 26, 209-217, 2004.

20 Stamm, C., Fluhler, H., Gachter, R., Leuenberger, J., and Wunderli, H.: Preferential transport of phosphorus in drained grassland soils, J. Environ. Qual., 27, 515-522, 1998.

Stehouwer, R. C., Dick, W. A., and Traina, S. J.: Characteristics of earthworm burrow lining affecting atrazine sorption, J. Environ. Qual., 22, 181-185, 1993.

Stone, W. W. and Wilson, J. T.: Preferential flow estimates to an agricultural tile drain with implications for glyphosate transport, J. Environ. Qual., 35, 1825-1835, 2006.

Tiemeyer, B., Kahle, P., and Lennartz, B.: Phosphorus losses from an artificially drained rural lowland catchment in North-Eastern Germany, Agric. Water Manag., 96(4), 677-690, 2009.

Turner, R. R. and Steele, K. F.: Cadmium and manganese sorption by soil macropore linings and fillings, Soil Sci., 145, 79-86, 1988.

30 van Genuchten, M. T.: A closed-form equation for predicting the hydraulic conductivity of unsaturated soils, Soil Sci. Soc. Am. J., 44, 892-898, 1980.

Vervoort, R. W., Radcliffe, D. E., and West, L. T.: Soil structure development and preferential solute flow, Water Resour. Res., 35, 913-928, 1999.
HESSD

8, 5917-5967, 2011

\section{Mass transfer effects in 2-D-DPERM modeling}

H. H. Gerke et al.

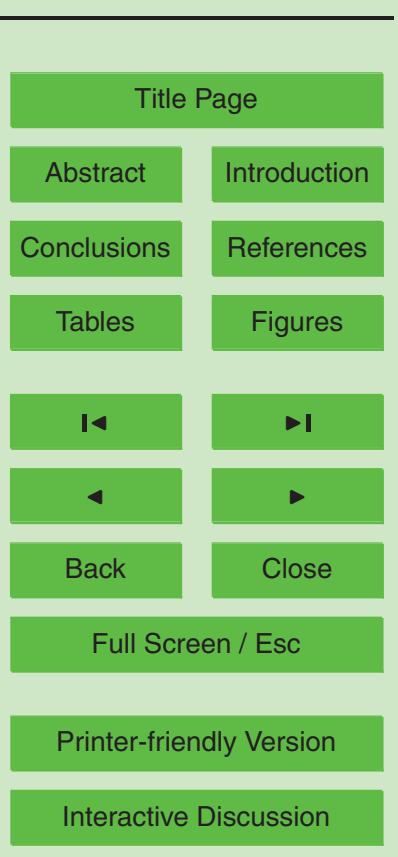


Vidon, P. and Cuadra, P. E.: Impact of precipitation characteristics on soil hydrology in tiledrained landscapes, Hydrol. Process., 24(13), 1821-1833, 2010.

Villholth, K. G. and Jensen, K. H.: Flow and transport processes in a macroporous subsurfacedrained glacial till soil. II: Model analysis, J. Hydrol., 207, 121-135, 1998.

5 Vogel, T. and Císlerová, M.: On the reliability of unsaturated hydraulic conductivity calculated from the moisture retention curve, Transport Porous Med., 3, 1-15, 1988.

Vogel, T., Gerke, H. H., Zhang, R., and van Genuchten, M. T.: Modeling flow and transport in a two-dimensional dual-permeability system with spatially variable hydraulic properties, J. Hydrol., 238, 78-89, 2000a.

10 Vogel, T., van Genuchten, M. T., and Cislerova, M.: Effect of the shape of soil hydraulic functions near saturation on variably-saturated flow predictions, Adv. Water Resour., 24, 133-144, doi:10.1016/S0309-1708(00)00037-3, 2000b.

Wichtmann, W., Lennartz, B., and Widmoser, P.: Bromidverlagerung an zwei gedränten Standorten in Schleswig-Holstein, J. Plant Nutr. Soil Sci., 161, 121-128, 1998 (in German).

Youngs, E. G. and Leeds-Harrison, P. B.: Aspects of transport processes in aggregated soils, J. Soil Sci., 41, 665-675, 1990.

Zehe, E. and Flühler, H.: Preferential transport of isoproturon at a plot-scale and a field-scale tile-drained site, J. Hydrol., 247, 100-115, 2001.

\section{HESSD}

$8,5917-5967,2011$

\section{Mass transfer effects in 2-D-DPERM modeling}

H. H. Gerke et al.

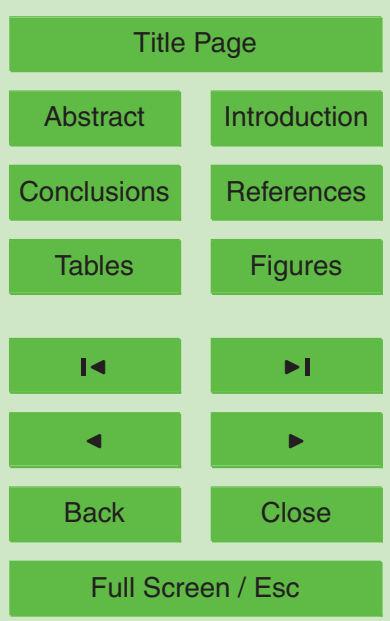

Printer-friendly Version

Interactive Discussion 


\section{HESSD}

8, 5917-5967, 2011

\section{Mass transfer effects}

in 2-D-DPERM

modeling

Table 1. Hydraulic parameters used for soil matrix (SM-) and preferential flow (PF-) domains assuming $w_{f}=0.05$ for both layers (i.e., $\theta_{\mathrm{s}}$ is saturated and $\theta_{\mathrm{r}}$ residual water content $\left(\mathrm{L}^{3} \mathrm{~L}^{-3}\right)$, respectively; $h_{\mathrm{s}}$ is air-entry value (L); $n(-)$ and $\alpha_{\mathrm{VG}}\left(\mathrm{L}^{-1}\right)$ are empirical shape parameters and $K_{\mathrm{s}}$ is saturated hydraulic conductivity $\left(\mathrm{LT}^{-1}\right)$. Anisotropy of hydraulic conductivity $\left(K_{x x} / K_{z z}=3\right)$ was assumed in $40-200 \mathrm{~cm}$ depth.

\begin{tabular}{lrrrrrrr}
\hline Layer & $\begin{array}{r}\text { Depth } \\
(\mathrm{cm})\end{array}$ & $\begin{array}{r}\theta_{\mathrm{r}} \\
\left(\mathrm{cm}^{3} \mathrm{~cm}^{-3}\right)\end{array}$ & $\begin{array}{r}\theta_{\mathrm{s}} \\
\left(\mathrm{cm}^{3} \mathrm{~cm}^{-3}\right)\end{array}$ & $\begin{array}{r}h_{\mathrm{s}} \\
(\mathrm{cm})\end{array}$ & $\begin{array}{r}\alpha_{\mathrm{VG}} \\
\left(\mathrm{cm}^{-1}\right)\end{array}$ & $\begin{array}{r}n \\
(-)\end{array}$ & $\begin{array}{r}K_{\mathrm{s}} \\
\left(\mathrm{cm} \mathrm{d}^{-1}\right)\end{array}$ \\
\hline SM-domain & $0-30$ & 0.001 & 0.333 & -37.4 & 0.001 & 1.362 & 3 \\
& $30-200$ & 0.001 & 0.332 & -0.84 & 0.044 & 1.169 & 5 \\
PF-domain & $0-30$ & 0.001 & 0.6 & 0 & 0.046 & 4.141 & 300 \\
& $30-200$ & 0.001 & 0.6 & 0 & 0.05 & 2.0 & 500 \\
\hline
\end{tabular}

H. H. Gerke et al.

Title Page

Abstract Introduction

Conclusions References

Tables Figures

14

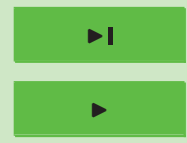

Back

Close

Printer-friendly Version

Interactive Discussion 


\section{HESSD}

$8,5917-5967,2011$

Mass transfer effects

in 2-D-DPERM modeling

H. H. Gerke et al.

Table 2. Dual-permeability (DPERM) mass transfer rate coefficients (relative) for water, $\alpha_{\text {ws }}$, and solute exchange, $\alpha_{\mathrm{ss}}$, used in the simulation scenarios.

\begin{tabular}{|c|c|c|c|c|c|c|}
\hline \multirow[b]{3}{*}{ Layer } & \multirow[b]{3}{*}{$\begin{array}{r}\text { Depth } \\
(\mathrm{cm})\end{array}$} & \multicolumn{5}{|c|}{ Mass transfer rate coefficients } \\
\hline & & \multirow{2}{*}{$\begin{array}{r}\alpha_{\mathrm{ws}} \\
\left(\mathrm{cm}^{-1} \mathrm{~d}^{-1}\right)\end{array}$} & \multicolumn{4}{|c|}{$\alpha_{\mathrm{ss}}$} \\
\hline & & & "Highest" & $\begin{array}{l}\text { "High" } \\
\qquad\left(d^{-1}\right)\end{array}$ & "Low" & "Lowest" \\
\hline Ap & 0-30 & 0.01 & 2 & 0.2 & 0.02 & 0.002 \\
\hline Subsoil & $30-200$ & 0.005 & 1 & 0.1 & 0.01 & 0.001 \\
\hline
\end{tabular}

Title Page

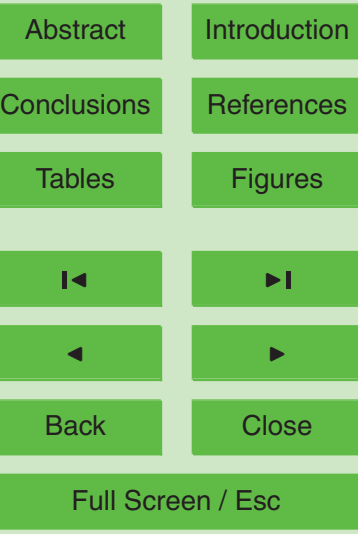

Printer-friendly Version

Interactive Discussion 


\section{HESSD}

$8,5917-5967,2011$

\section{Mass transfer effects}

in 2-D-DPERM

modeling

Table 3. Summary of the solute balances for the period 97-103 days: Total cumulative bromide mass leached with drain effluent (Leached $\mathrm{Br}$ ), simulated minus measured values (Diff_Br), and Nash-Sutcliffe (N-S) criterion for each scenario; $555 \mathrm{~g}$ leached bromide was measured and $4300 \mathrm{~g}$ applied.

\begin{tabular}{lccc}
\hline $\begin{array}{l}\text { Simulation } \\
\text { scenario }\end{array}$ & $\begin{array}{c}\text { Leached } \\
\mathrm{Br}(\mathrm{g})\end{array}$ & $\begin{array}{c}\text { Diff_Br } \\
(\mathrm{g})\end{array}$ & $\begin{array}{c}\text { N-S criterion } \\
\text { for } \mathrm{Br}(-)\end{array}$ \\
\hline Lowest & 648 & 93 & 0.646 \\
Low & 632 & 77 & 0.659 \\
High & 528 & -27 & 0.530 \\
Highest & 402 & -153 & 0.181 \\
\hline
\end{tabular}

H. H. Gerke et al.

Title Page

Abstract Introduction

Conclusions

References

Tables

Figures

I

4

Back

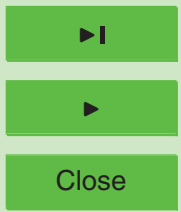

Full Screen / Esc

Printer-friendly Version

Interactive Discussion 


\section{HESSD}

8, 5917-5967, 2011

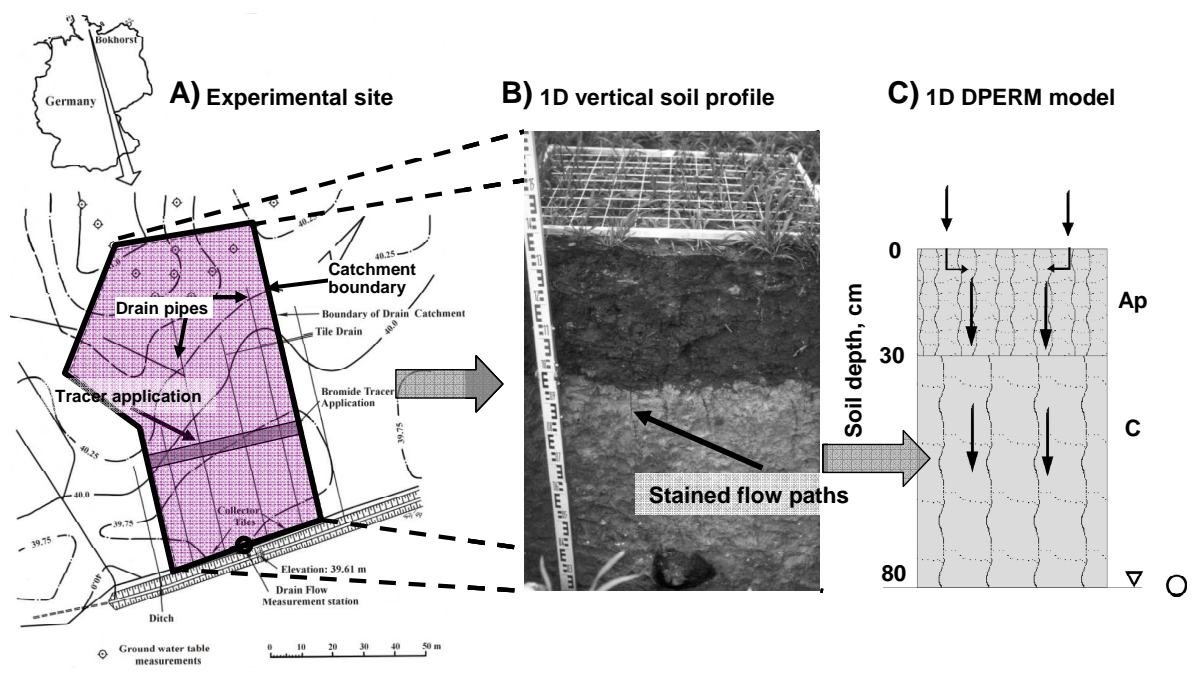

\section{Mass transfer effects in 2-D-DPERM modeling}

H. H. Gerke et al.

Fig. 1. Abstraction of the subsurface-drained catchment "Bokhorst" as 1-D vertical dualpermeability model (1D DPERM) representation for (A) location and conditions of the experimental site, (B) photo of the upper $1 \mathrm{~m}$ soil depth, and (C) two layer model with "effective" soil properties and structural differences between the top- and the subsoil; a water table and the location of the drain in $0.8 \mathrm{~m}$ depth are indicated.

Abstract

Conclusions

References

Tables

Figures

14

4

Back

Close

Full Screen / Esc

Printer-friendly Version

Interactive Discussion 


\section{HESSD}

8, 5917-5967, 2011

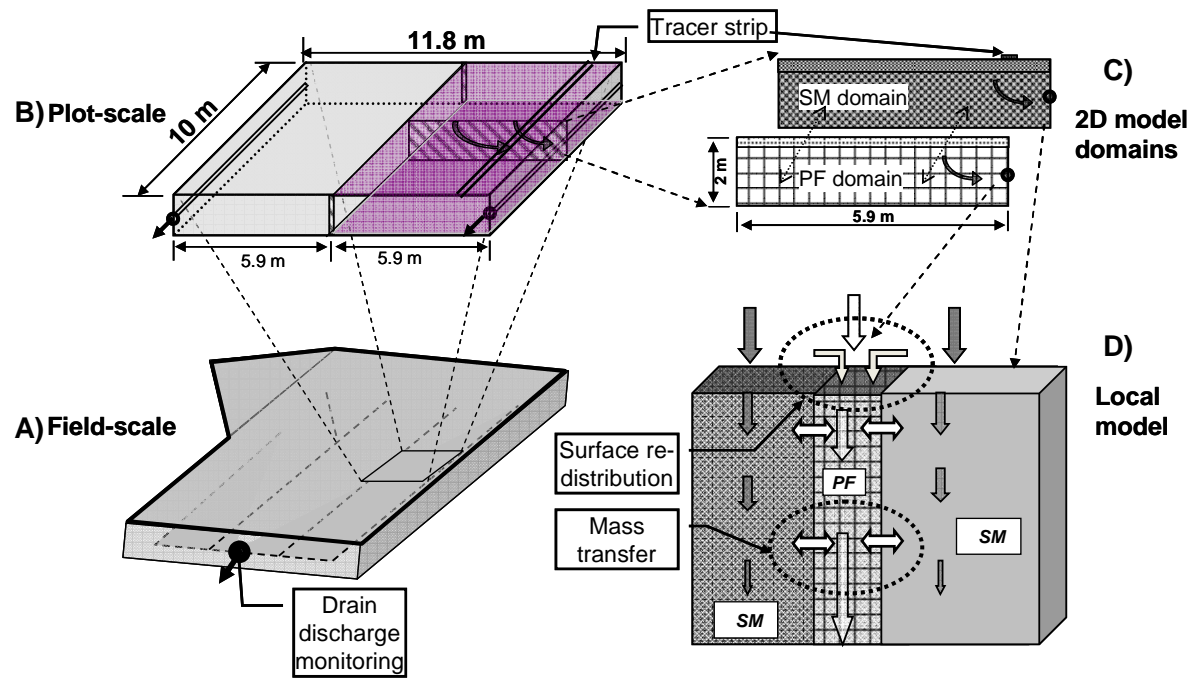

\section{Mass transfer effects in 2-D-DPERM modeling}

H. H. Gerke et al.

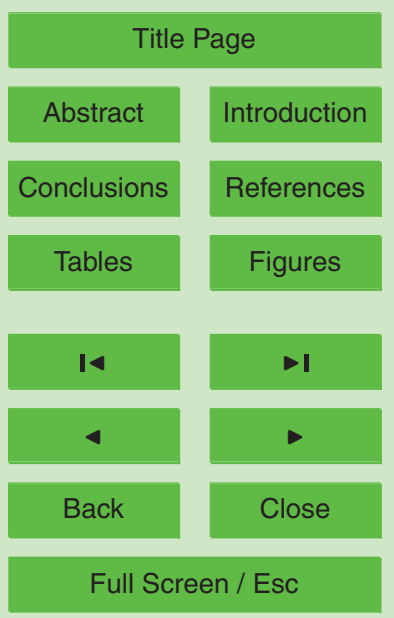

Fig. 2. Schematic spatial configurations and scale relations of the subsurface-drained catchment for the 2-D dual-permeability model (2D-DPERM) representation for (A) field-scale with the irrigation experimental plot and the drain discharge monitoring station, (B) plot-scale with tracer application, irrigation and 2-D model domains (c.f., Dusek et al., 2008), (C) the 2-D dualpermeability model domain scale with two 2-D domains and exchange and location of the drain, and (D) the local model scale indicating domain-specific infiltration, surface redistribution and subsurface mass transfer between the PF and SM domains.

Printer-friendly Version

Interactive Discussion 


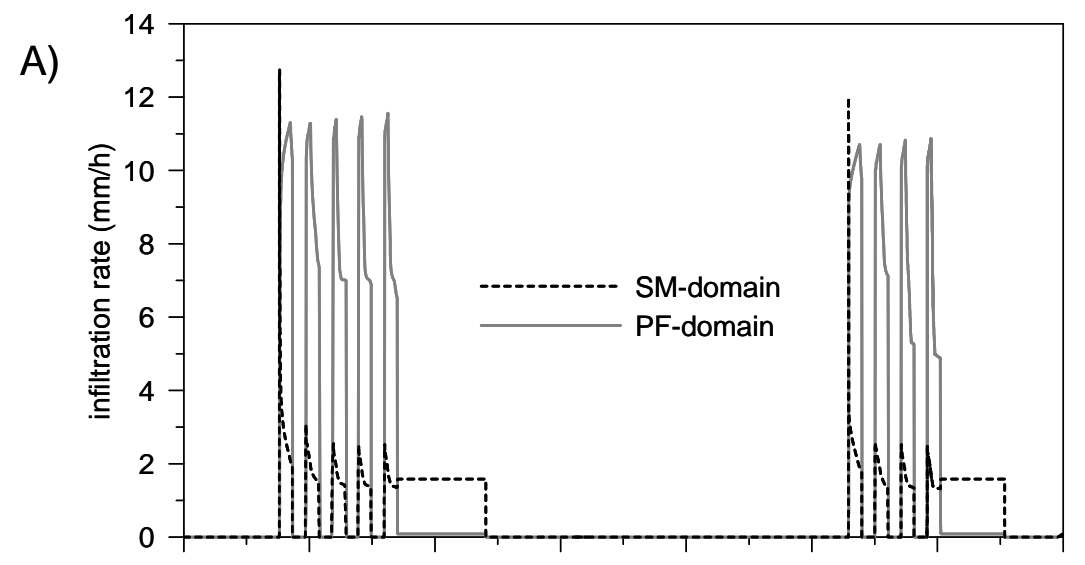

\section{HESSD}

8, 5917-5967, 2011

\section{Mass transfer effects} in 2-D-DPERM modeling

H. H. Gerke et al.

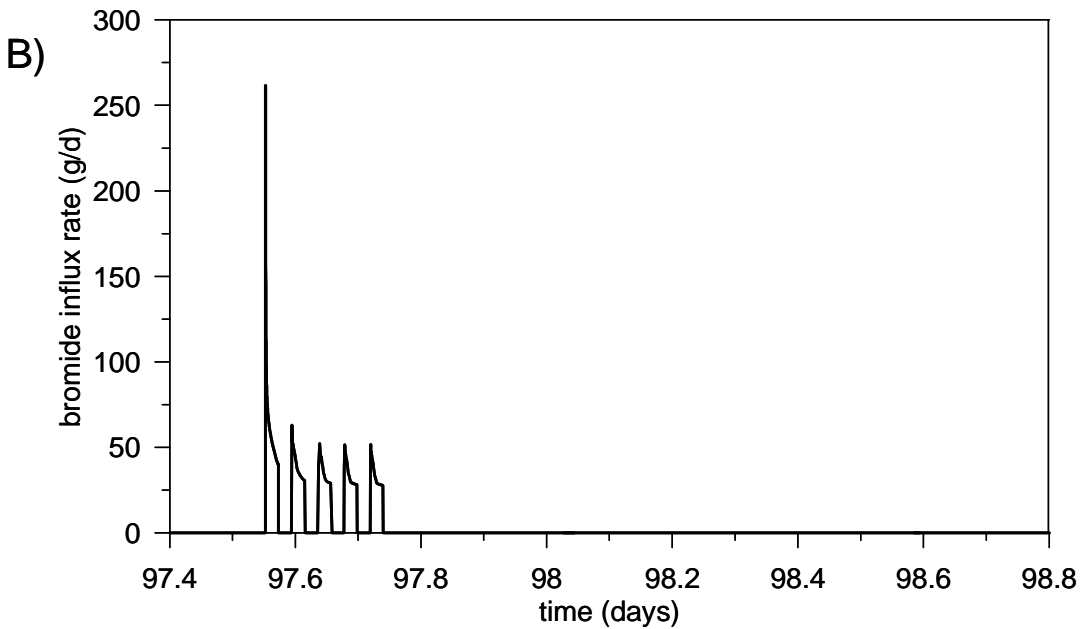

\section{Title Page}

Abstract Introduction

Conclusions References

Tables

Figures

14

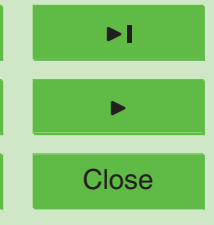

Back

Close

\section{Full Screen / Esc}

Printer-friendly Version

Fig. 3. Upper boundary conditions used in the 2D-DPERM model during the two days of irrigation for (A) infiltration in the SM and PF domains and (B) the assumed $\mathrm{Br}$ influx in the SM domain.

Interactive Discussion

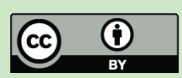




\section{HESSD}

8, 5917-5967, 2011

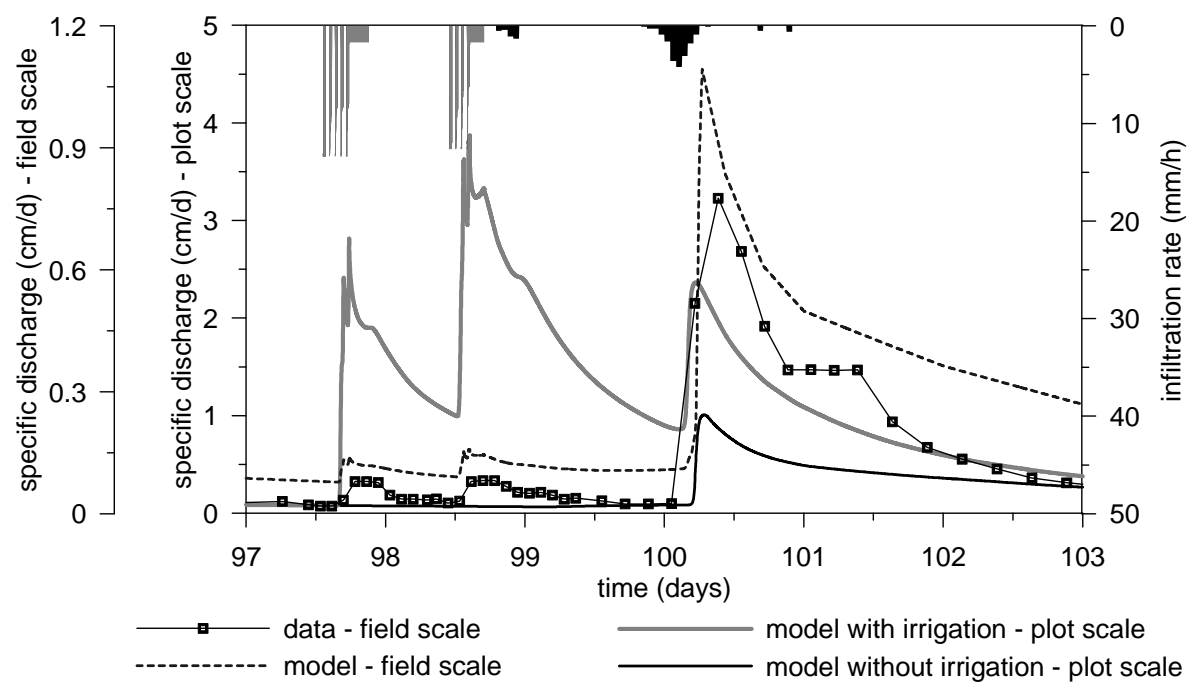

\section{Mass transfer effects in 2-D-DPERM modeling}

H. H. Gerke et al.

\section{Title Page}

Abstract Introduction

Conclusions References

Tables

Figures

14

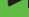

Back

Close

\section{Full Screen / Esc}

Printer-friendly Version

Interactive Discussion 


\section{HESSD}

8, 5917-5967, 2011

Mass transfer effects in 2-D-DPERM modeling

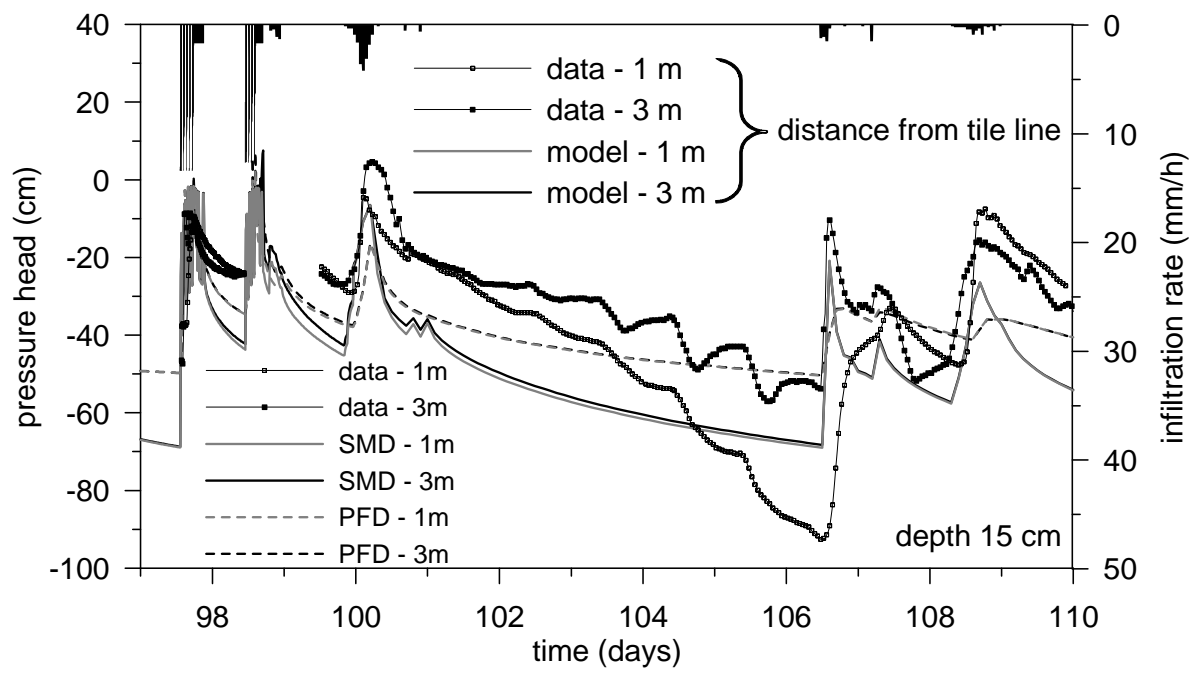

Fig. 5. Comparison of measured and two-domain simulated soil water pressure head curves in $15 \mathrm{~cm}$ soil depth at two locations in $1 \mathrm{~m}$ and $3 \mathrm{~m}$ from the tile line during the irrigation period, the rain, and a following infiltration-free period (Days 97-110).
H. H. Gerke et al.

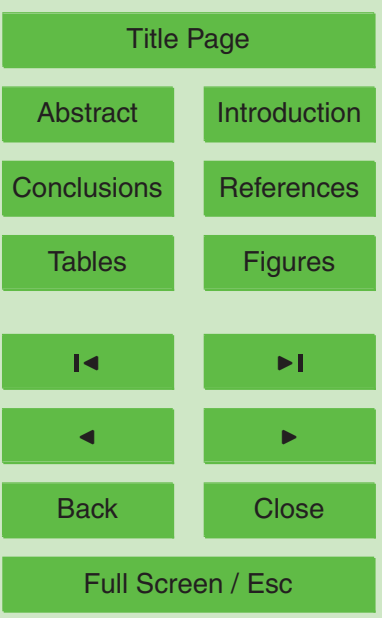

Printer-friendly Version

Interactive Discussion 


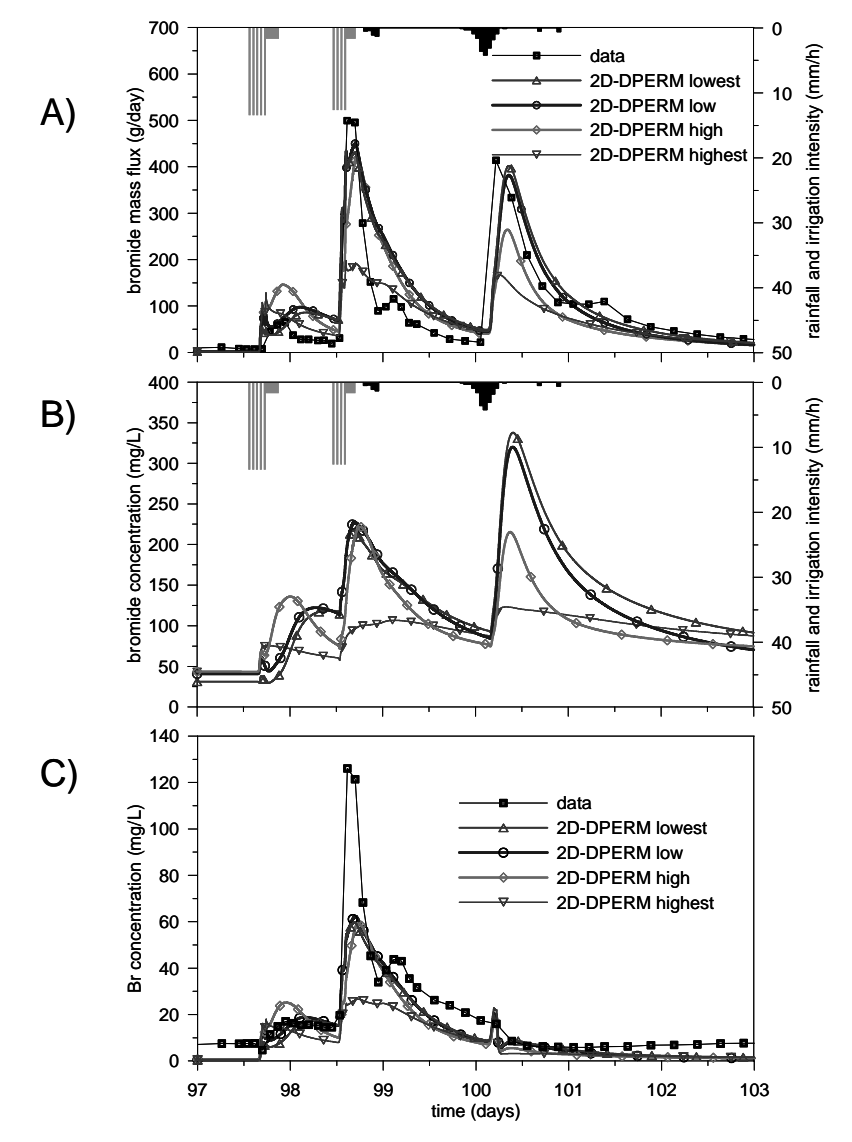

\section{HESSD}

8, 5917-5967, 2011

\section{Mass transfer effects in 2-D-DPERM modeling}

H. H. Gerke et al.

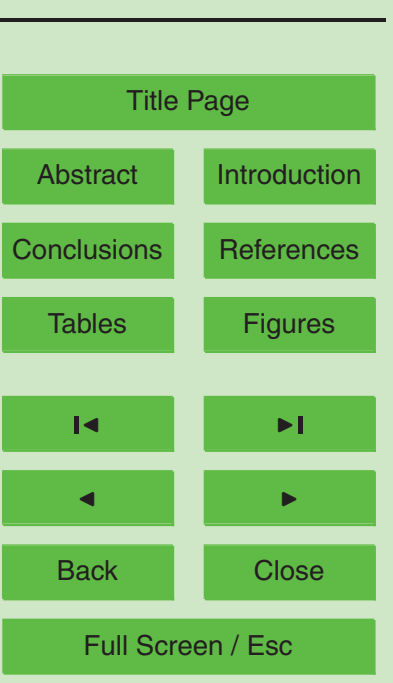

Fig. 6. Effect of the solute mass transfer rate coefficient, $\alpha_{\mathrm{ss}}$, (i.e., 2D-DPERM highest, high, low, lowest, Table 2) on $\mathrm{Br}^{-}$leaching during the period (Days 97-103) for (A) $\mathrm{Br}$ mass flux comparing field-scale simulations with data, (B) plot-scale simulated $\mathrm{Br}^{-}$effluent concentrations, and (C) field-scale simulated $\mathrm{Br}^{-}$effluent concentrations compared with measured $\mathrm{Br}^{-}$ concentrations for all four mass transfer scenarios. 


\section{HESSD}

8, 5917-5967, 2011

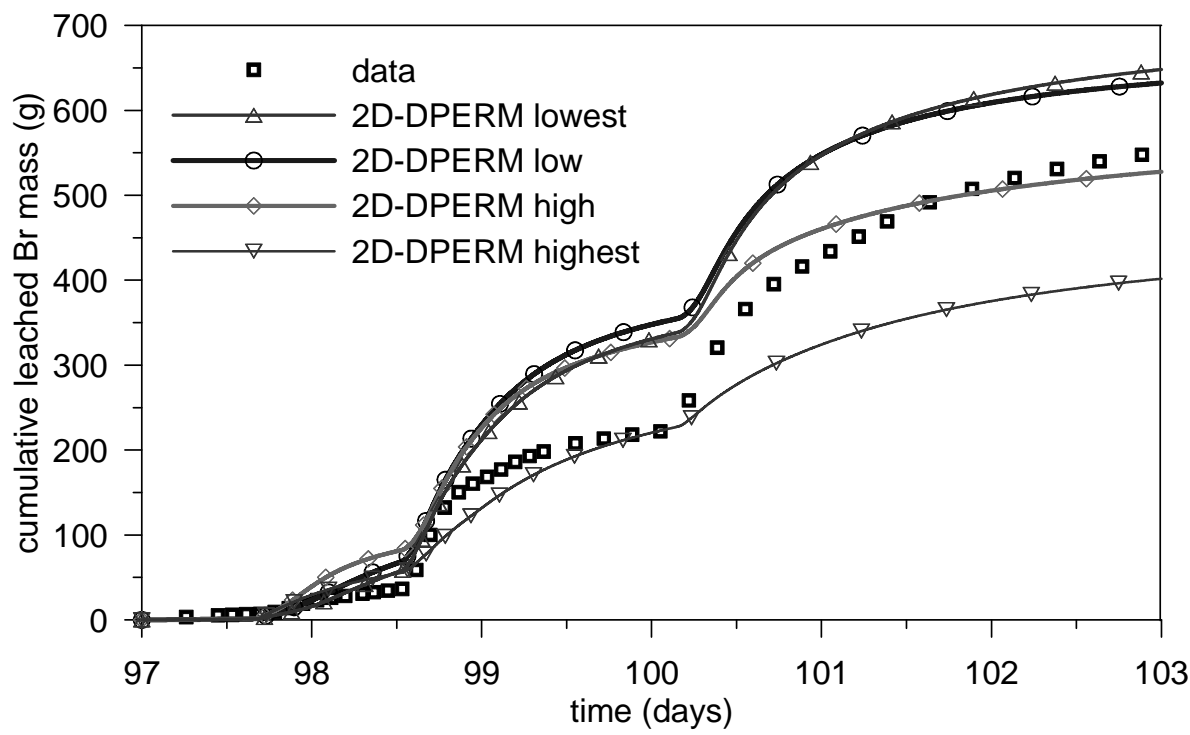

Mass transfer effects in 2-D-DPERM modeling

H. H. Gerke et al.

\section{Title Page}

Abstract

Introduction

Conclusions

References

Tables

Figures

14

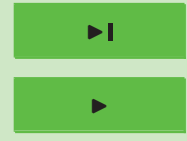

Back

Close

Full Screen / Esc

Printer-friendly Version

Interactive Discussion 
A)

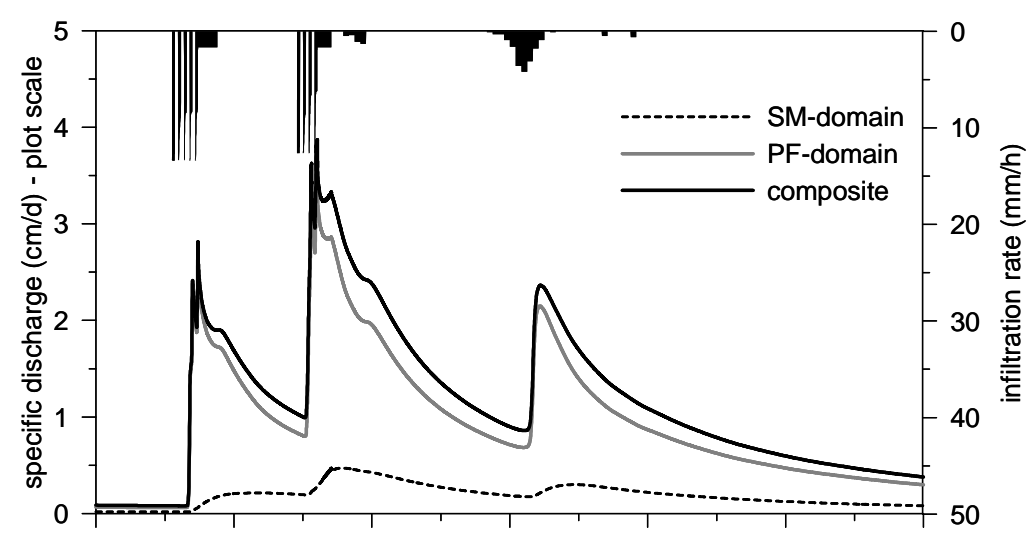

B)

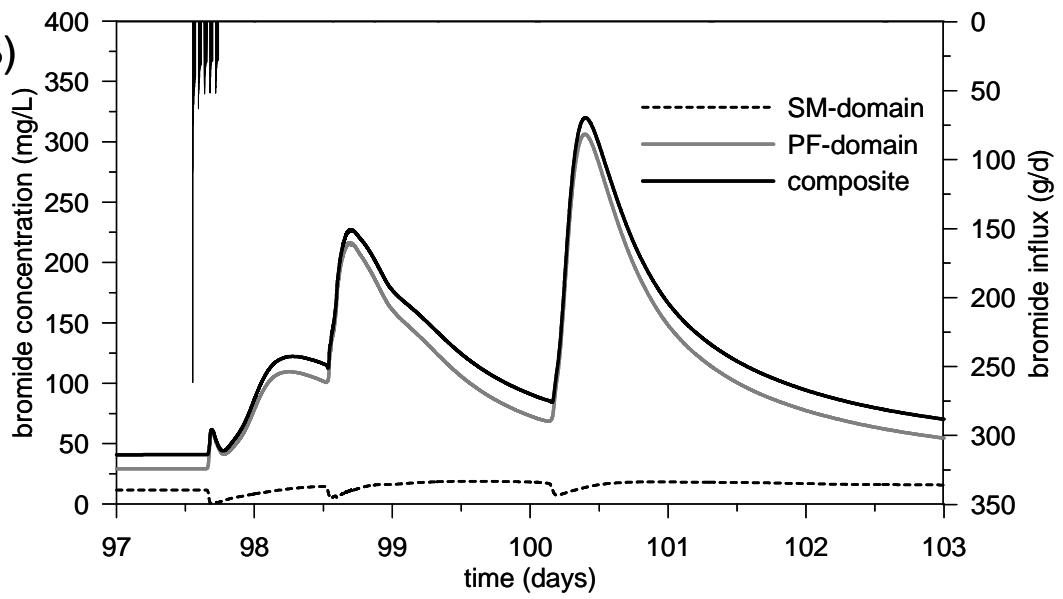

Fig. 8. Plot-scale simulated composite (whole soil pore volume) and contributions of specific contributions of the soil matrix (SM) and the preferential flow (PF) domains to (A) specific drain discharge and (B) $\mathrm{Br}^{-}$concentration in drain effluent for the scenario with the low $\alpha_{\mathrm{ss}}$ value (Table 2) during the period Days 97-103.

\section{HESSD}

8, 5917-5967, 2011

Mass transfer effects in 2-D-DPERM modeling

H. H. Gerke et al.

\section{Title Page}

Abstract Introduction

Conclusions References

Tables

Figures

14 I

4

Back

Close

\section{Full Screen / Esc}

Printer-friendly Version

Interactive Discussion 


\section{HESSD}

8, 5917-5967, 2011

\section{Mass transfer effects}

in 2-D-DPERM

modeling

H. H. Gerke et al.

\section{Title Page}

Abstract

Introduction

Conclusions

References

Negativ: $S M \rightarrow P F$

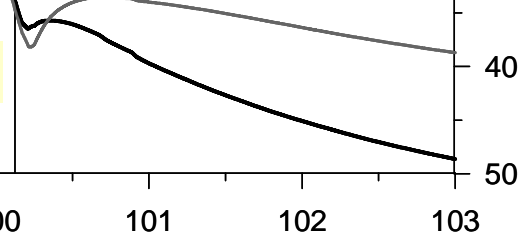

98

99

100

Fig. 9. Cumulative inter-domain water mass transfer simulated for the period Days 97-103 for a scenario that assumes infiltration of rainfall and irrigation as compared to a scenario of rainfall only (without irrigation); vertical lines indicate times during irrigation (Day 97.73) and rain (Day 100.125).

Tables

14

4

Back
Figures

$>1$

$>$

Close

\section{Full Screen / Esc}

Printer-friendly Version

Interactive Discussion 


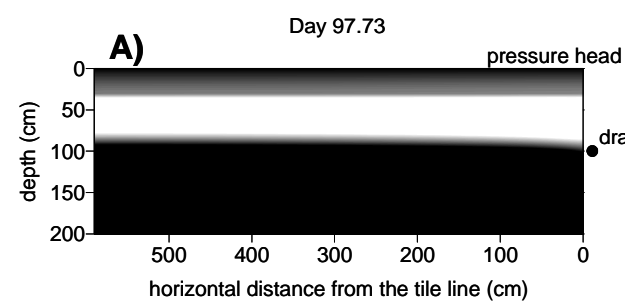

Day 100.125

\section{HESSD}

$8,5917-5967,2011$

\section{Mass transfer effects in 2-D-DPERM \\ modeling}

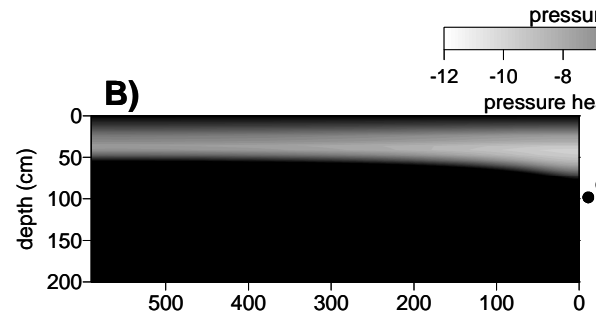

$\begin{array}{lllll}500 & 400 & 300 & 200 & 100 \\ \text { horizontal distance from the tile line }(\mathrm{cm})\end{array}$

H. H. Gerke et al.

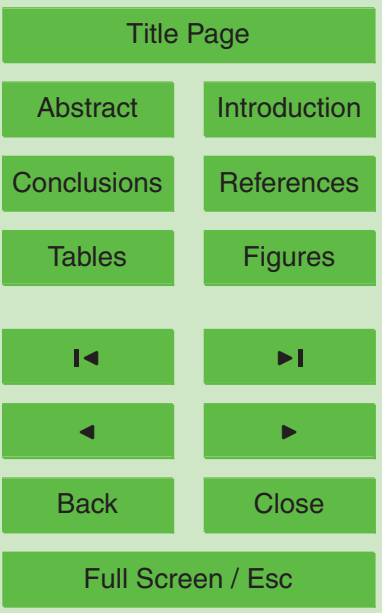

Fig. 10. Simulated 2-D spatial distributions of soil water pressure heads in $(\mathbf{A})$ the soil matrix (SM) domain and (B) the preferential flow (PF) domain, and (C) 2-D distributions of water exchange between the two domains as obtained with the 2D-DPERM flow model during irrigation (Day 97.73, left panels) and during rain (Day 100.125, right panels).
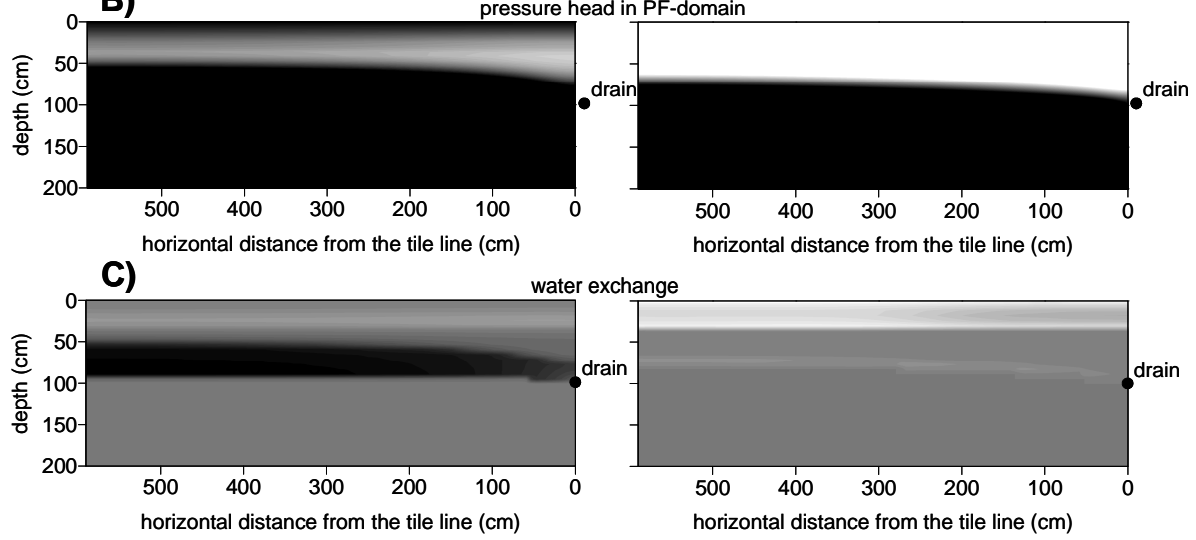

water transfer $(1 / \mathrm{d})$

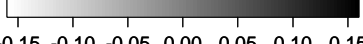

\section{Full Screen / Esc}

Printer-friendly Version

Interactive Discussion 


\section{HESSD}

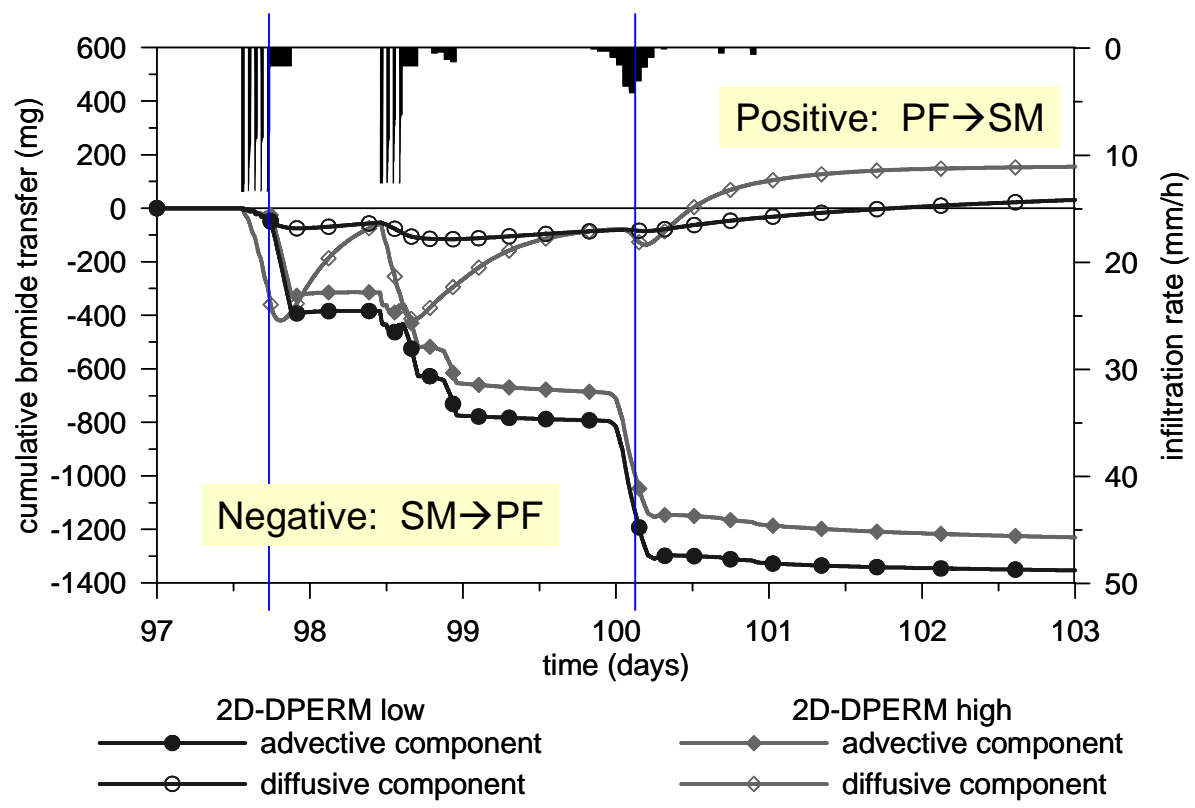

\section{$8,5917-5967,2011$}

Mass transfer effects in 2-D-DPERM modeling

H. H. Gerke et al.

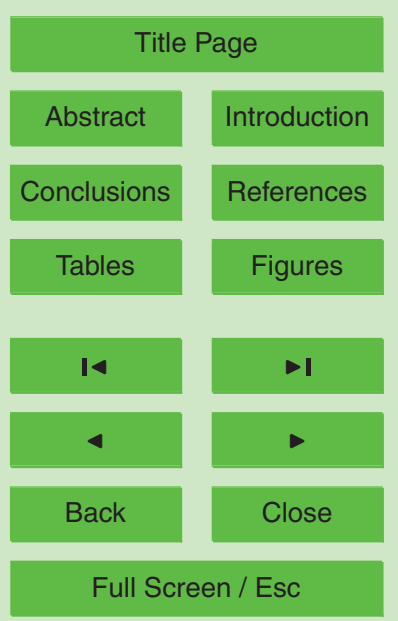

Fig. 11. Cumulative inter-domain $\mathrm{Br}$ mass transfer components simulated for the period Day 97-103 for scenarios that assume relatively "low" and "high" values of the mass transfer coefficient, $\alpha_{\mathrm{ss}}$, and plotted separately for "advective" $\mathrm{Br}^{-}$transfer (i.e., due to exchange of water) and "diffusive" $\mathrm{Br}^{-}$transfer (i.e., due to concentration differences between domains); vertical lines indicate times during irrigation (Day 97.73) and rain (Day 100.125).

Printer-friendly Version

Interactive Discussion 

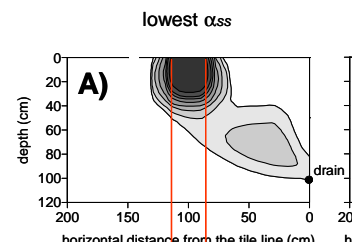

low $\alpha$ ss

high $\alpha s s$
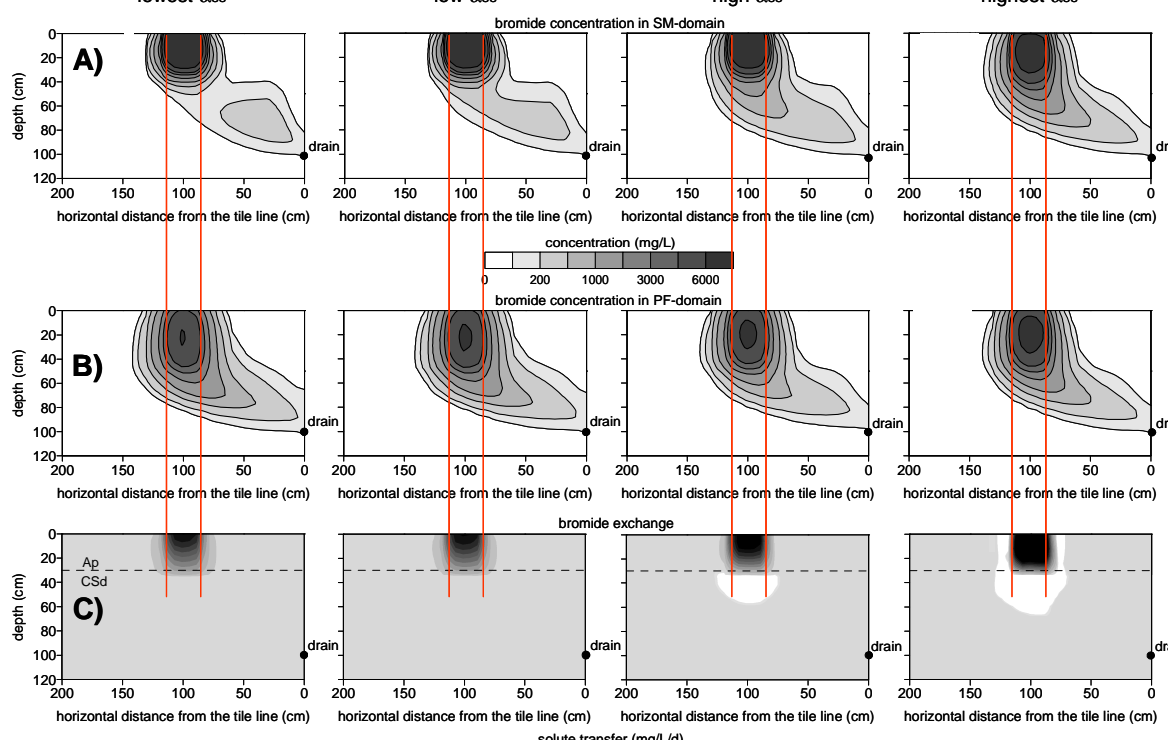

olute transfer (mg/L/d)

Fig. 12. Simulated 2-D spatial distributions of residual $\mathrm{Br}^{-}$concentrations in the soil for the scenarios "lowest", "low", "high", and "highest" values (i.e., vertical panels) of the mass transfer coefficient, $\alpha_{\mathrm{ss}}$, and at Day 101.125 for (A) the soil matrix (SM) domain and (B) the preferential flow (PF) domain; in (C) the distributions of the solute mass transfer is given; only the region between 0 and $200 \mathrm{~cm}$ horizontal distance from the drain underneath the $30 \mathrm{~cm} \mathrm{Br}$ application strip, indicated by vertical lines, is presented.
HESSD

8, 5917-5967, 2011

Mass transfer effects in 2-D-DPERM modeling

H. H. Gerke et al.

\section{Title Page}

Abstract Introduction

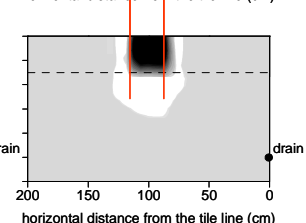

Conclusions

References

Tables

Figures

14

4

Back

Close

\section{Full Screen / Esc}

Printer-friendly Version

Interactive Discussion 